\title{
Multiple Immune-Inflammatory and Oxidative and Nitrosative Stress Pathways Explain the Frequent Presence of Depression in Multiple Sclerosis
}

\author{
Gerwyn Morris ${ }^{1}$ - Edna Maria Vissoci Reiche ${ }^{2}$ - Andrea Murru ${ }^{3}$ - André F. Carvalho ${ }^{4}$ Michael Maes ${ }^{5}$. \\ Michael Berk ${ }^{1,6,7,8,9}$ - Basant K. Puri ${ }^{10}$
}

Received: 25 September 2017 / Accepted: 14 December 2017 / Published online: 2 January 2018

(C) The Author(s) 2017. This article is an open access publication

\begin{abstract}
Patients with a diagnosis of multiple sclerosis (MS) or major depressive disorder (MDD) share a wide array of biological abnormalities which are increasingly considered to play a contributory role in the pathogenesis and pathophysiology of both illnesses. Shared abnormalities include peripheral inflammation, neuroinflammation, chronic oxidative and nitrosative stress, mitochondrial dysfunction, gut dysbiosis, increased intestinal barrier permeability with bacterial translocation into the systemic circulation, neuroendocrine abnormalities and microglial pathology. Patients with MS and MDD also display a wide range of neuroimaging abnormalities and patients with MS who display symptoms of depression present with different neuroimaging profiles compared with MS patients who are depression-free. The precise details of such pathology are markedly different however. The recruitment of activated encephalitogenic Th17 T cells and subsequent bidirectional interaction leading to classically activated microglia is now considered to lie at the core of MS-specific pathology. The presence of activated microglia is common to both illnesses although the pattern of such action throughout the brain appears to be different. Upregulation of miRNAs also appears to be involved in microglial neurotoxicity and indeed T cell pathology in MS but does not appear to play a major role in MDD. It is suggested that the antidepressant lofepramine, and in particular its active metabolite desipramine, may be beneficial not only for depressive symptomatology but also for the neurological symptoms of MS. One clinical trial has been carried out thus far with, in particular, promising MRI findings.
\end{abstract}

Keywords Depression · Multiple sclerosis · Immune function · Inflammation · Desipramine $\cdot$ Lofepramine $\cdot$ Oxidative and nitrosative stress

Basant K. Puri

basant.puri@imperial.ac.uk

1 IMPACT Strategic Research Centre, School of Medicine, Deakin University, Barwon Health, Geelong, Australia

2 Department of Pathology, Clinical Analysis, and Toxicology, Health Sciences Center, State University of Londrina, Londrina, Paraná, Brazil

3 Bipolar Disorders Program, Hospital Clínic Barcelona, IDIBAPS, CIBERSAM, Barcelona, Spain

4 Department of Clinical Medicine and Translational Psychiatry Research Group, Faculty of Medicine, Federal University of Ceará, Fortaleza, CE, Brazil
5 Department of Psychiatry, Faculty of Medicine, Chulalongkorn University, Bangkok, Thailand

6 Department of Psychiatry, Medical University Plovdiv, Plovdiv, Bulgaria

7 Department of Psychiatry, Faculty of Medicine, State University of Londrina, Londrina, Brazil

8 Revitalis, Waalre, The Netherlands

9 Orygen - The National Centre of Excellence in Youth Mental Health, The Department of Psychiatry and the Florey Institute for Neuroscience and Mental Health, The University of Melbourne, Parkville, Australia

10 Department of Medicine, Imperial College London, Hammersmith Hospital, London, UK 


\section{Introduction}

Multiple sclerosis (MS) is the most common inflammatory, demyelinating, neurodegenerative disease of the central nervous system (CNS) and is the leading source of non-traumatic neurological disability among young adults in Europe and North America [1,2]. The wide array of core neurological symptoms associated with this illness includes sensory disturbances, limb weakness, optic neuritis, ataxia, profound bladder dysfunction, cognitive dysfunction, gastro-intestinal symptoms, fatigue and depression [2,3]. Therefore, MS is viewed as a heterogeneous phenotype, and an expert consensus has proposed some discrete courses for this illness, including a clinically isolated syndrome, a relapsing-remitting disease, and progressive forms of the disease.

In 1887, Jean-Martin Charcot noted that a significant proportion of patients with MS display neuropsychiatric disturbances throughout the course of the illness. Since then, a significant body of evidence has accumulated and indicated that depressive symptoms represent the most prevalent of such neuropsychiatric disturbances seen in MS patients $[4,5]$. The prevalence of depressive symptoms in MS patients has varied across studies. A systematic review and meta-analysis of population-based studies has estimated a prevalence of $23.7 \%$ (95\% CI: $17.4-30.0 \%$ ) [6], while prevalence rates seem to be substantially higher in specialised clinics (up to $50 \%$ ) [4].

A growing body of evidence indicates that patients displaying symptoms of depression have a worse prognosis than those who do not. It is noteworthy that prospective data indicate that mood symptoms fluctuate over the course of MS and that the advent of depressive symptoms is often associated with disease relapse.

The presence of depressive symptoms is predictive of an impaired quality of life and such symptoms can either co-exist with severe fatigue and/or significant cognitive impairment or occur independently. Cognitive impairment may affect up to $60 \%$ of patients with MS [7-9] and the severity of depressive symptoms correlates with increased impairment in executive function and processing speed [10,11]. Depression also is a significant contributor to the higher suicide rates observed among individuals with MS, with the standardised mortality ratio for suicide in such patients being around twice as high as that in the general population [12].

Major depressive disorder (MDD) is increasingly regarded as a unitary and very serious neuroprogressive illness with a remitting-relapsing pattern leading to major disability and reduction in life quality together with increased cardiovascular and other significant medical morbidity [13]. This illness is currently estimated to be the fourth leading cause of serious disability in the world and is projected to become the second leading cause of disabling morbidity worldwide by 2020 [14]. The question arises as to whether the high rates of depressive symptoms seen in MS patients represent the same condition as MDD and is the assumption that some patients with MS also have MDD as a separate illness correct or are such symptoms a manifestation of the core disease processes driving the pathogenesis and pathophysiology of the latter illness [15]. In this context, it is intriguing that there is accumulating evidence suggesting that there may be some common elements underpinning the pathogenesis and pathophysiology of MDD and MS. For example, it is noteworthy that neuroinflammation and neurodegeneration are both considered to be crucial elements in the pathogenesis and pathophysiology of both MS and MDD [16-18]. The weight of evidence also indicates that this is also true of peripheral inflammation as evidenced by elevated levels of proinflammatory cytokines (PICs), acute-phase proteins, such as C-reactive protein (CRP), and transcriptional factors, such as nuclear factor kappa B (NF-kB) $[19,20]$. Indeed, increased rates of peripheral inflammation, notably interleukin (IL)-6 and CRP, appear to differentiate MS patients suffering from comorbid depression from those who do not [21]. Interestingly, there is also some evidence to suggest patients reporting symptoms of depression also present with more advanced disease and increased clinical disability, as measured by the Expanded Disability Status Scale (EDSS), compared with their depression-free counterparts, although whether these findings indicate that depressive symptoms emanate from core disease processes or whether the advent of MDD is an independent driver of pathology remains an open question [21].

MS and MDD patients share many other abnormalities, such as chronic oxidative and nitrosative stress (O\&NS) characterised by oxidatively and nitrosatively damaged proteins, lipids and DNA, and consequent loss of immunogenic tolerance [22]. Given the strong association between chronic oxidative stress and the development of mitochondrial dysfunction, the presence of widespread damage to this organelle in both illnesses is unsurprising $[19,20]$. Impaired natural killer (NK) cell function and/or reduced numbers of these lymphocytes are also characteristic features of MDD and MS [23, 24]. Disturbed T cell homeostasis and recruitment of myelin autoreactive encephalogenic T cells into the CNS is still considered to be the ultimate driver of progressive pathology in MS, but there is also a growing awareness that impaired $\mathrm{T}$ cell homeostasis and recruitment into the CNS may well play an important role in the pathophysiology of MDD [17]. Further evidence of impaired T cell homeostasis in both illnesses is provided by several research groups who have reported abnormalities in function and/or number of regulatory T cells (Tregs) $[25,26]$. Functional polymorphisms affecting cytokine production and/or function and $\mathrm{T}$ cell homeostasis and activation increase the risk of developing both illnesses [27-29].

Epigenetic dysregulation is also seen in MS and MDD with widespread changes in DNA methylation, histone acetylation and microRNA (miRNA) transcription leading to the 
abnormal expression of a multitude of genes, although the precise pattern of altered gene expression is markedly different $[30,31]$. However, despite copious research, the mechanisms underpinning the pathogenesis of both illnesses remain to be fully delineated and the contributions of many of the abnormalities to disease pathology are still the subject of some controversy. The situation is made more complex by evidence indicating that MDD and MS are very likely pathologically heterogeneous conditions $[32,33]$. While there is a growing consensus that inflammation in the periphery and the brain together with oxidative stress and mitochondrial dysfunction play a role in the aetiopathogenesis of both illnesses, there are major differences in abnormalities recorded in many other domains such as $\mathrm{T}$ cell dysfunction $[16,18,19]$.

The precise biological mechanisms underpinning the existence of depression in MS and their importance in contributing to the pathophysiology of MS are still the subject of some debate. In addition, as previously indicated, the issue remains outstanding as to whether depressive symptomology accompanying MS can be regarded either as evidence of the existence of MDD as a separate condition acting as a driver of pathology or be a product of core disease processes. In this paper, we aim to compare findings in MS and MDD produced by various research teams investigating immune abnormalities, glial cell activity, blood brain barrier permeability [34], autoimmune manifestations, impaired gastrointestinal epithelial barrier permeability, activity of inflammatory pathways, neuroimaging and bioenergetics in order to comment on the likely answer or answers to this question or indeed whether such a dichotomous viewpoint is appropriate. Finally, we suggest translational implications for this expanding body of knowledge.

\section{Methods}

Pursuant to our interest in comparing and contrasting a wide range of biological abnormalities in MS and MDD, a search of MEDLINE and Web of Science was undertaken with keyword inputs of MS, depression, T cell, B cell, oxidative stress, nitrosative tress, nitric oxide (NO), mitochondrial dysfunction, inflammation, immune activation, microglia, astrocytes, neuroinflammation, neoepitopes, autoimmunity, antioxidants, antioxidant therapy, gut dysbiosis, increased intestinal permeability, leaky gut, bacterial translocation, epigenetic, histone acetylation, DNA methylation and microRNA.

\section{Evidence of O\&NS in MS and MDD}

\section{O\&NS in MS}

There are multiple lines of evidence demonstrating that chronic O\&NS plays a major causative role in the pathogenesis of
MS [18, 19, 35]. Such evidence includes data demonstrating dramatic increases in O\&NS levels during relapse, which falls to virtually undetectable levels when patients enter into remission [36]. Levels of O\&NS also correlate with the extent of clinical disability as ascertained by the EDSS score and the extent of gadolinium-enhanced lesions observed with structural magnetic resonance imaging (MRI) scanning [37, 38]. Furthermore, Tasset and fellow workers have reported significant peripheral levels of oxidative stress in patients with relapsing-remitting MS (RRMS) [39, 40]. Several research teams have reported the presence of O\&NS damage to proteins and lipids, such as elevated levels of protein carbonyls in the brain, cerebrospinal fluid (CSF) and peripheral blood of MS patients in vivo and in post mortem studies [19, 41, 42]. Several other surrogate markers of O\&NS and lipid peroxidation are frequently observed in the CSF and plasma of MS patients $[42,43]$, with the presence of malondialdehyde (MDA) [44], hydroxynonenal [41] and isoprostanes [45] being the most common findings. Interestingly, and perhaps predictably, levels of NO metabolites in the CSF correlate positively with the number of relapses suffered by a patient over a given period [46]. Unsurprisingly, significantly increased levels of NO, peroxynitrite and superoxide are also present in spinal fluid extracts [44] and high levels of nitrotyrosine, indicating the presence of peroxynitrite and inducible NO synthase (iNOS) are often reported in active demyelinated white matter lesions [44, 47].

\section{O\&NS in MDD}

O\&NS, resulting from increased reactive oxygen species (ROS), reactive nitrogen species (RNS) and compromised cellular antioxidant systems, is also considered to be a major factor driving the pathophysiology of MDD [48-50]. Evidence of compromised antioxidant system activity includes elevated levels of superoxide dismutase and catalase activity [51] and deficiencies in levels of antioxidant molecules, such as vitamins $C$ and E [52-54]. Several authors have also reported the presence of widespread lipid peroxidation in the prefrontal cortex and other crucial areas of the brain linked to the development of MDD [55, 56]. Interestingly, lipid peroxidation levels correlate with symptom severity in females but not in males for reasons which remain to be delineated [55, 56]. The presence of lipid peroxidation is reinforced by data demonstrating the existence of increased MDA concentrations in serum and extensive oxidative damage to a wide range of lipids in peripheral tissues [51, 57]. Several research teams have also reported increased levels of isoprostane and 8-oxo$2^{\prime}$-deoxyguanosine in urine and plasma samples, bearing further testimony to the presence of high ROS and RNS levels produced outside the brain in patients suffering from depression [52-54]. In this context, it is noteworthy that the levels of 
peripheral oxidative stress markers correlate with severity and chronicity in both male and female patients [50, 56-58].

Given this relationship, the presence of a large number of papers reporting the results of trials into the efficacy of antioxidant compounds as potential antidepressant treatments is unsurprising $[59,60]$. Furthermore, the extent of oxidative damage to proteins, lipids and DNA is of sufficient magnitude as to form neoepitopes owing to loss of immunological tolerance leading to autoantibody responses and the development of autoimmunity [49, 61, 62]. The presence of oxidative damage to mitochondrial DNA (mtDNA) observed in patients suffering from MDD is further evidence of the severity of peripheral nitroxidative stress associated with this illness $[63,64]$.

\section{Evidence of Lowered Antioxidant Levels}

\section{Antioxidants in MS}

There is ample evidence of lowered serum total antioxidant capacity in MS patients with reduced levels of plasma albumin ascorbate, alpha tocopherol, retinol urate and bilirubin compared with healthy controls being repeatedly reported [65-67]. Altered glutathione homeostasis, especially reduced glutathione reductase and glutathione peroxidase, is also a well-documented phenomenon although some research teams have not observed such abnormalities in their study cohorts $[68,69]$. The activity of the thioredoxin system is also compromised in at least some patients diagnosed with this illness with increased thioredoxin activity but impaired thioredoxin reductase activity being the most commonly reported findings [70]. Superoxide dismutase and catalase activities are increased in grey matter, microglia, lesions and the CSF, but impaired in peripheral blood mononuclear cells (PBMCs) and erythrocytes in the periphery [71-74]. Finally, there are several studies reporting increased activity of the transcription factor nuclear factor (erythroid-derived 2)-like 2 (NFE2L2 or $\mathrm{Nrf2}$ ) and of antioxidant response elements (ARE) in the brain and periphery but that this increased activity is unable to prevent the oxidative damage to molecules in the environment of chronically increased ROS and RNS seen in MS patients [70, $75,76]$.

Several antioxidant regimes have demonstrated clinical and neurological benefit in non-human animal models of MS but results in humans, in whom very high doses of antioxidants are needed to achieve functional effects in the CNS, have been relatively disappointing until relatively recently. However, activators of Nrf2-ARE signalling pathway such as dimethyl fumarate (DMF) are now showing considerable promise [77, 78]. Activation of this pathway has several beneficial consequences, such as activation of the haem oxygen pathway and increased synthesis of reduced glutathione, inhibition of
$\mathrm{NF}-\mathrm{KB}$ and PIC production, and a concomitant provocation of a Th1 to Th2 lymphocyte shift [79, 80]. The authors of the CONFIRM and DEFINE studies were the first to report a significant decrease in the annual relapse rate, reductions in the number of gadolinium-enhanced MRI lesions and new or hyper-intense legions in patients treated with DMF compared with interferon (IFN)- $\beta[81,82]$. These findings have been confirmed by several other research teams [83-85]. MitoQ has been successful in delaying progression and reducing neurological disability in experimental autoimmune encephalomyelitis (EAE) [86] and standard formulations of coenzyme $\mathrm{Q}_{10}(\mathrm{CoQ} 10)$ at $500 \mathrm{mg} /$ day have demonstrated a capacity to reduce inflammatory markers in people with MS [87]. However, there are no studies demonstrating any benefit on neuroimaging indices or clinical disability although $\mathrm{CoQ} 10$ at $500 \mathrm{mg} /$ day appears to produce a significant reduction in the symptoms of fatigue and depression in MS patients [88]. Polyunsaturated fatty acids (PUFAs) are another class of nutrients which have shown clinical and neurological improvement in some MS patients albeit at very high doses for prolonged periods of time [89]. However, while PUFAs clearly have antioxidant effects, their mode of action is multifactorial and these entities affect very similar pathways to those influenced by DMF [90].

\section{Antioxidant Levels in MDD}

MDD patients characteristically display significantly lower serum concentrations of a wide array of crucial antioxidants, such as zinc, ascorbic acid and CoQ10 [91]. Several research teams have also reported lower plasma total antioxidant status compared with unaffected controls [92-94]. There is also evidence of impaired activity of the glutathione system with reduced levels of reduced, oxidised and total glutathione reported in the post mortem brains of MDD patients [94]. The concentration and activity of key enzymes within the glutathione system, namely glutathione peroxidase and glutathione-Stransferase, also appear to be reduced in the brain and periphery of patients suffering from this illness [95, 96]. While there is limited published work investigating the status of the thioredoxin system in MDD patients [97], there is ample evidence of abnormal MnSOD and catalase activity [98-100]. Catalase activity appears to be consistently increased but the data for MnSOD are somewhat inconsistent with reports of both increased serum activity $[98,99]$ and decreased serum activity [100]. There is no direct evidence of abnormal Nrf2 or DJ-1 (PARK7) activity in MDD patients although there is some evidence from animal studies suggesting that the expression of Nrf2 may be reduced [101].

While several classes of antioxidants have proven to be efficacious in treating depression in animal models of the illness, the overall results in human studies have been rather disappointing especially as far as unipolar depression is 
concerned (review $[92,102])$. There are some data demonstrating that $1200 \mathrm{mg}$ CoQ10 per day over 8 weeks can significantly reduce depressive symptoms in patients with bipolar disorder [103, 104] and a recent study by Gaultan and others demonstrated a significant treatment effect in unipolar depression using vitamins $\mathrm{C}$ (in the form of ascorbic acid), $\mathrm{E}$ (as alpha-tocopherol) and $\mathrm{A}$ (as beta-carotene) over a 6-week period [105]. A meta-analysis of 241 studies concluded that supplements containing eicosapentaenoic acid (EPA) and docosahexaenoic acid appeared to convey significant benefit in treating MDD if the EPA content was greater than $50 \%$ of the total concentration [106]. A reader interested in a more detailed examination of these studies is invited to consult a review by [89]. Therapeutic administration of $N$ acetylcysteine has demonstrated therapeutic benefit in a number of illnesses in which chronic inflammation and oxidative stress play a major pathogenic role (reviewed [89]). Disappointingly, it only demonstrated slight non-significant effects on symptom reduction in MDD [59], although the doses used in this trial were significantly lower than the doses proven to convey therapeutic benefit in other inflammatory illnesses [18]. Meta analyses of $N$-acetylcysteine however seem to show a positive signal [107]. The use of polyphenols such as apigenin, amentoflavone, chlorogenic acid, ferulic acid, resveratrol and curcumin have recently attracted a great deal of attraction following their success in non-human animal studies and their broad range of positive effects on inflammation, oxidative stress, mitochondrial dysfunction, intestinal permeability and serotoninergic and dopaminergic neurotransmission $[108,109]$. Lopresti and colleagues reported a significant improvement in symptoms in patients with MDD following $1000 \mathrm{mg} /$ day of curcumin, particularly those patients suffering from depression with atypical features [108]. However, replication of these results in larger samples is due before definitive conclusions can be made regarding the therapeutic benefit of this supplement. A summary of similarities and differences between MS and MDD in the redox domain is provided by Table 1 .

\section{Evidence of Peripheral Inflammation in MS and MDD}

\section{Peripheral Inflammation in MS}

There is now copious evidence of the distribution patterns and levels of a wide range of PICs and anti-inflammatory cytokines in the CSF, post mortem brains and serum of patients diagnosed with RRMS and indeed all other presentations of the disease [110-112]. Examples of elevated PICs include IFN- $\gamma$, tumour necrosis factor (TNF)- $\alpha$, IL-12 IL-1 $\beta$, IL-6, IL-15, IL-4, IL-17, IL-10, transforming growth factor (TGF)- $\beta 1$, IL-27 and IL-23 $[112,113]$. It is noteworthy that
Table 1 Similarities in O\&NS pathways and antioxidant levels between MS and MDD

\begin{tabular}{lcc}
\hline O\&NS & MS & MDD \\
\hline Lipid peroxidation & $\mathrm{Y}$ & $\mathrm{Y}$ \\
Increased malondialdehyde & $\mathrm{Y}$ & $\mathrm{Y}$ \\
Elevated peroxynitrite & $\mathrm{Y}$ & $\mathrm{Y}$ \\
Nitrated amino acids & $\mathrm{Y}$ & $\mathrm{Y}$ \\
Elevated NO & $\mathrm{Y}$ & $\mathrm{Y}$ \\
Elevated iNOS & $\mathrm{Y}$ & $\mathrm{Y}$ \\
Raised isoprostane levels & $\mathrm{Y}$ & $\mathrm{Y}$ \\
Low vitamin E & $\mathrm{N}$ & $\mathrm{Y}$ \\
Reduced levels of glutathione & $\mathrm{Y}$ & $\mathrm{Y}$ \\
Low zinc levels & $\mathrm{N}$ & $\mathrm{Y}$ \\
Low CoQ10 concentrations & $\mathrm{N}$ & $\mathrm{Y}$ \\
O\&NS implicated in pathology & $\mathrm{Y}$ & $\mathrm{Y}$ \\
\hline
\end{tabular}

the overall pattern of cytokine abnormalities seen in patients in the active phase of the illness differs from that characteristically observed in patients who have entered remission [106, 109]. In particular, elevated levels of TGF- $\beta 1$ and IL- 10 are characteristic of the latter individuals while elevated levels of PICs, most notably TNF- $\alpha$, IL- $1 \beta$ and IFN- $\gamma$, are characteristic of patients following relapse $[110,113]$.

Importantly, increasing levels of TNF- $\alpha$ in the peripheral circulation are predictive of relapse and levels of this PIC correlate with clinical disability estimated by EDSS scores $[110,114,115]$. Levels of TNF- $\alpha$ correlate with the severity of fatigue experienced by many MS patients, which has a major detrimental impact on their quality of life [116]. It is also noteworthy that functional single nucleotide polymorphisms (SNPs) in several genes encoding TNF superfamily members would appear to be the largest non-human leukocyte antigen (HLA) risk factors for developing the illness with the $T N F-\beta$ Ncol polymorphism rs 909253 , in the first intron of $T N F-\beta$, conferring the greatest risk $[113,114]$. There is an accumulating body of evidence demonstrating that this SNP combined with elevated O\&NS is associated with a marked increase in disease progression and levels of clinical disability and unsurprisingly the TNF- $\beta$ Ncol polymorphism rs 909253 continues to be the focus of intense research $[117,118]$.

Levels of IL-6, CRP and other markers of systemic inflammation appear to be higher in MS patients reporting symptoms of depression compared with patients who do not report such symptoms [21]. It is also noteworthy that elevated levels of IL-6 are also associated with increased symptoms and increased severity of disease experienced by MS patients exposed to protracted periods of extreme psychosocial stress [119]. IL-1 $\beta$ is another PIC implicated in the pathogenesis and pathophysiology of MS $[116,117]$. In particular, the presence of this cytokine in the CSF of patients currently in remission foretells a poor prognosis and the development of a more 
aggressive disease profile as determined by EDSS [120]. In addition, detectable levels of IL- $1 \beta$ observed in the CSF of newly diagnosed treatment-naïve patients are an invariant marker of significant brain damage and correlate positively with cortical lesion volume [121].

Elevated CNS and serum levels of IL-17 are also commonly detected in MS patients [122, 123]. The multiple pathological effects of this cytokine include direct cellular and tissue damage as well as promotion of the maturation of dendritic cells and increased production of TNF- $\alpha$ [122]. The contribution made by IL-17 to the pathogenesis of RRMS is highlighted by data demonstrating that levels of IL-17 correlate with the frequency of relapses endured by a patient and are strongly predictive of the failure of IFN- $\beta$ therapy [122, 123]. The ultimate origin of cytokine abnormalities in MS appear to be activated $\mathrm{T}$ and $\mathrm{B}$ cells in the periphery while activated microglia B lymphocytes and monocytes are the major source of cytokines in the CSF [124].

Activation of the nucleotide-binding oligomerisation domain (NOD)-like receptor (NLR) family, pyrin domain containing 3 (NLRP3) inflammasome, also appears to be a source of PIC production, and the weight of evidence suggests that activated dendritic cells make an additional contribution [125, 126]. However, despite copious evidence implicating the pathogenic role of PICs and IL-17 in the development of RRMS, there are also data indicating that anti-inflammatory cytokines are drivers of pathology in some patients [127].

\section{Peripheral Inflammation in MDD}

There is a developing consensus which places chronic systemic inflammation, as evidenced by elevated PICs and/or a dysregulated pattern of cytokine production, as the ultimate driver of major depression [17, 128-130]. It is noteworthy that increased levels of peripheral PICs in combination with increased free ROS and RNS production go some way towards explaining the increased risk of developing cardiovascular, metabolic and other serious medical diseases in patients afforded a diagnosis of MDD compared with age- and sexmatched controls [131, 132]. Several meta-analyses have revealed that increased levels of Il- 6 and TNF- $\alpha$ would seem to be the most consistent findings in MDD patients, but elevated levels of IFN- $\gamma$ and IL- $1 \beta$ are also frequently reported [13, 133, 134]. The importance of PICs in the pathogenesis of MDD has been emphasised by recent evidence published by Young and fellow workers, who reported that the magnitude of peripheral PIC elevation correlated with the progression and severity of the disease [135]. This conclusion supports the work of earlier research teams who reported a correlation between levels of PICs in the CSF of MDD patients and the severity of symptoms they endured [26]. Moreover, Maes and fellow workers have established an association between the presence of functional SNPs in $T N F-\alpha, I L-1 \beta$ and $C R P$ and an increased risk of developing depression and, indeed, responsiveness or otherwise to the administration of antidepressant therapy [94].

The origin of PICs in MDD is thought to be M1 (classically activated) polarised macrophages and, possibly, neutrophils but there is also accumulating evidence of activated, if anergic, T cells in at least some MDD patients [94]. The activation of the NLRP3 inflammasome by danger-associated molecular patterns (DAMPs) (also known as damageassociated molecular patterns), such as heat-shock protein-72 (HSP72), mtDNA and uric acid, leading to the increased production of activated IL-1 $\beta$ and IL-18, may also be involved [27]. In the context of examining potential sources of inflammation in MDD patients, it is noteworthy that DAMPmediated activation of the NLRP3 inflammasome is potentiated by the presence of commensal lipopolysaccharide (LPS) translocated into the peripheral circulation as a result of increased intestinal permeability [136, 137], Translocated LPS is also a major cause of Toll-like receptor (TLR) activation on antigen-presenting cells (APCs) and hence a potential source of T cell activation in MDD [17, 137]. Readers interested in a detailed treatment of this area are referred to a comprehensive review by Lucas and colleagues [138].

This would seem to be an appropriate juncture to add words of caution, as while elevated PICs would appear to be major drivers of symptoms in MDD patients, this is not invariably so. It would appear that, in at least some patients, the symptoms are associated with increased levels of antiinflammatory cytokines, notably IL-4, IL-13 and IL-15, and the recovery is associated with increased levels of PICs, such as TNF- $\alpha$ [139]. This may reflect the fact that MDD is considered by many to be a biologically heterogeneous illness, as proposed by the latter authors, but there may also be other explanations. One such would be activation of the haemcontaining enzyme indoleamine 2,3-dioxygenase (IDO) by PICs or LPS and a pattern of immunosuppression following the subsequent increase in levels of the L-tryptophan metabolite kynurenine [91]. It is also conceivable that direct Treg activation by LPS could provoke a Th2-biased cytokine pattern [140]. Peripheral cytokines can access the CNS to provoke activation of microglia and astrocytes via several mechanisms, such as via the circumventricular organs, which lack a fully functional blood-brain barrier (BBB) [18]. This influx of peripheral PICs leads to activation of perivascular macrophages and endothelial cells, which in turn secrete cytokines and other inflammatory mediators, such as a range of chemokines, NO and prostaglandin E2 (PGE2) [17, 141]. The other major mechanisms involved in relaying cytokine signalling to the CNS involve the stimulation of vagal nerve afferents in the spleen conveying cytokine signals to brain regions such as the hypothalamus and are often described as the neural route [142]. We now move to a consideration of the similarities and differences of the patterns of microglial 
pathology in MS and MDD. A summary of similarities and differences between MS and MDD regarding abnormalities in immune and inflammatory pathways is provided in Table 2 .

\section{Evidence of Microglial Pathology in MS and MDD}

\section{Microglial Pathology in MS}

Several authors have reported the presence of activated microglia expressing the cell surface receptor HLA-antigen Drelated (HLA-DR), which (with its ligand) is a T cell receptor ligand, in the normal-appearing white matter (NAWM) of RRMS patients in the earliest stages of the disease even in the absence of BBB disruption [143, 144]. It is also noteworthy that the extent of microglial activation in the later stages of RRMS is associated with a worse prognosis and also correlates positively with the level of disability as ascertained by the EDSS score [145, 146]. Microglial actions in MS lesions can be dichotomised into the activities of M1 and M2 (alternatively activated) microglia (sometimes respectively designated as neurotoxic and neuroprotective). Neuroprotective microglia carry out their benign role by secreting a range of neurotrophic factors and also play a major role in aiding clearance of myelin and other debris and thus can be considered to have an anti-inflammatory and calming effect within the CNS [147]. Neurotoxic microglia, on the other hand, can provoke and accelerate the development of neuroinflammation via the secretion of PICs, ROS, RNS, PGE2, cyclooxygenase-2

Table 2 Similarities and differences in immune-inflammatory biomarkers between MS and MDD

\begin{tabular}{lcc}
\hline Immuno-inflammatory pathways & MS & MDD \\
\hline Raised levels of PICs & $\mathrm{Y}$ & $\mathrm{Y}$ \\
Increased NF-kB & $\mathrm{Y}$ & $\mathrm{Y}$ \\
Increased COX-2 & $\mathrm{Y}$ & $\mathrm{Y}$ \\
Raised IL-2 & $\mathrm{Y}$ & $\mathrm{Y}$ \\
Raised IL-10 & $\mathrm{N}$ & $\mathrm{Y}$ \\
Raised TGF- $\beta$ & $\mathrm{Y}$ & $\mathrm{N}$ \\
Co-existence of a Th1 and Th2 response & $\mathrm{Y}$ & $\mathrm{Y}$ \\
Presence of IL-17-secreting Th17 T cells & $\mathrm{Y}$ & $\mathrm{Y}$ \\
Temporal variation in cytokine profile & $\mathrm{Y}$ & $\mathrm{Y}$ \\
Astrocyte activation and or dysfunction & $\mathrm{Y}$ & $\mathrm{Y}$ \\
Treg dysfunction & $\mathrm{Y}$ & $\mathrm{Y}$ \\
FOXP3 dysfunction & $\mathrm{Y}$ & $?$ \\
Clonal exhaustion of T cells & $\mathrm{N}$ & $\mathrm{Y}$ \\
Activated microglia and macrophages & $\mathrm{Y}$ & $\mathrm{Y}$ \\
Intrathecal IgG production & $\mathrm{Y}$ & $\mathrm{N}$ \\
Low NK cell activity & $\mathrm{Y}$ & $\mathrm{Y}$ \\
Chronic activation of immuno-inflammatory pathways & $\mathrm{Y}$ & $\mathrm{Y}$ \\
\hline
\end{tabular}

(COX-2), quinolinic acid and glutamate [20, 148, 149]. Importantly, from the perspective of the pathogenesis and the pathophysiology of the disease, the polarisation of these glial cells into neurotoxic or neuroprotective phenotypes is heavily influenced and perhaps even determined by the environmental balance of microRNAs (miRNAs) in the environment, with increases in miR-689, miR-124 and miR-155 being associated with the development of an M1 phenotype while miR-124, miR-711 and miR-145 appear to mediate polarisation into an M2 phenotype [150]. In this context, it is important to note that the production of miR-155 is upregulated in microglia of RRMS patients and is a recognised driver of PIC synthesis and secretion [151]. The mechanisms underpinning these observations have yet to be fully delineated but it is noteworthy that there are data indicating that the transcription of mi-155 and mi-145 is responsive to levels of NF-KB, PICs and Nrf2 [152, 153]. Microglia also have the capacity to act as APCs, thereby activating naïve autoreactive $\mathrm{T}$ cells recruited from the peripheral circulation [146]. The recruitment of $\mathrm{T}$ cells from the periphery appears to play a crucial role in the pathogenesis and pathophysiology of RRMS and determines the pathological or benign consequences of microglial activation [154]. In particular, the influx of inflammatory encephalitogenic $\mathrm{CD} 4^{+} \mathrm{T}$ cells, including Th17, Th1 and $\gamma \delta \mathrm{T}$-cells, robustly promote the development of neuroinflammatory and neurodegenerative processes while recruitment of Tregs and Th2 ameliorate neuroinflammation stemming from microglial activation thereby playing a major role in the development of an anti-inflammatory and neurosupportive environment $[155,156]$.

\section{Microglial Pathology in MDD}

Several research teams have also reported the existence of activated microglia in patients afforded a diagnosis of MDD $[157,158]$. Sustained activation of these glial cells would appear to be the ultimate source of the neuroinflammation seen in most, but by no means all, MDD patients [157, 159]. The weight of evidence implicating the presence of activated microglia as a causative factor in the pathogenesis and pathophysiology of MDD is accumulating so rapidly that one team of researchers has even described idiopathic MDD as "a microglial disease" [160]. The putative role of activated microglia in the initiation and progression of the illness is further reinforced by the existence of data demonstrating that the severity of symptoms experienced by MDD patients correlates with levels of quinolinic acid, which is a neurotoxin secreted by these glial cells in an activated state [161], and that the activation of microglia underpins the development of $N$-methyl-D-aspartate (NMDA) receptor excitotoxicity [158]. It is also of interest that many, if not all, antidepressants modulate the function and morphology of microglia and this property may well underpin their therapeutic effects seen in some 
patients [160]. However, there appear to be significant differences in the pattern of microglial activation in the hippocampus in MDD patients compared with the pattern seen in RRMS patients. Microglial pathology in MS is described in the previous subsection, while in the case of MDD the initial activation and proliferation of these glial cells is replaced by cell death in the form of apoptosis and/or a myriad of morphological changes which include reduced expression of a wide array of essential functional proteins indicative of profound dystrophy [162].

Interestingly, the development of dystrophy appears to be preventable in animal models of MDD by the early administration of the tetracycline-class antibiotic minocycline [162], which also demonstrates early efficacy signals in depression $[163,164]$. Abnormalities in miRNA expression patterns have also been reported in the brains of MDD patients, but once again, the overall pattern seems to be significantly different from that detected in RRMS patients. Specifically, in the case of abnormalities in their levels, miRNA species appear focused on those playing a major role in modulating and enabling the many "housekeeping" roles of microglia in the CNS such as maintaining neuroplasticity, regulating longterm potentials involved in the development and consolidation of learning and memory, and the global performance of innate and adaptive immune signalling pathways within the brain [157]. There is some evidence of increased recruitment of Tregs into the CNS in MDD [26, 165]. This phenomenon may be of importance given data demonstrating that Tregs reduce levels of microglial activation and thus act to restrain the development of neuroinflammation [151, 152]. This would appear to be an important point as the recruitment of Tregs into the CNS in "idiopathic" MDD versus the pattern of Th17 and Th1 T cell recruitment into the CNS in RRMS may, at least in part, explain the different patterns of microglial pathology seen in each condition.

\section{Evidence of Mitochondrial Dysfunction in MS and MDD}

\section{Mitochondrial Dysfunction in MS}

While the weight of evidence indicates that inflammation and O\&NS are the prime drivers of pathology in early MS, the ultimate trajectory of disease progression is heavily influenced by mitochondrial dysfunction and impaired production of adenosine triphosphate (ATP) in the brain and periphery $[166,167]$. The range of mitochondrial abnormalities observed in MS includes altered cellular distribution and structure together with a wide range of biochemical and molecular abnormalities [20, 168-170]. Impaired activity of Complex I (reduced nicotinamide adenine dinucleotide (NADH)-Q oxidoreductase) of the electron transport chain (ETC) and extensive oxidative damage to mtDNA are characteristically observed in active MS lesions [171], while the activities of Complex I, Complex III (Q-cytochrome $c$ oxidoreductase), and Complex IV (cytochrome $c$ oxidase) are also impaired in NAWM of the motor cortex and elsewhere [172-174]. Complex IV activity is also decreased in normal-appearing grey matter (NAGM) as well as in white matter hyperintensities [173, 174].

Several authors using neurospectroscopy have reported the presence of lactate in the CSF of MS patients and a range of abnormalities consistent with globally impaired bioenergetics $[175,176]$. A recent longitudinal study conducted by Lazzarino and colleagues provided support for the causative role of mitochondrial dysfunction in the pathophysiology of MS when they reported that progressive depletion of central ATP levels correlated with increased physical disability as measured by EDSS changes over a 3-year period [177]. Even more recently, a different group reported that not only did RRMS and secondary progressive MS (SPMS) patients have higher phosphocreatine (PCr) and lower phosphodiesters than age-matched healthy controls, but a higher $\beta$-ATP level was found in RRMS patients than in SPMS patients, with its level correlating negatively with the EDSS score in all the MS patients; these findings suggest a higher level of energy production in the former MS group, which might be related to an increased energy need than in the SPMS group [178].

$\mathrm{N}$-acetylaspartate (NAA) levels can be measured in the brain using proton neurospectroscopy and is of particular interest because of its neuronal localisation [179]. Using a combination of diffusion tensor imaging and proton neurospectroscopy, in 2012 Wood and colleagues reported lower NAA parallel diffusivity $(\lambda)$ in MS patients compared with age- and sex-matched controls [180]. They also found that NAA $\lambda$ was inversely correlated with water $\lambda$ and with clinical severity [174]. These results were consistent with axonal degeneration in MS. Five years later, the same group published the results of a six-month diffusion-weighted proton neurospectroscopy study in MS, reporting a decrease in NAA diffusivity in patients with evidence of inflammatory activity but not in those with neuroradiological and clinical stability [181]. Thus, this technique can be used to assess the downstream effects of acute inflammatory demyelination [175].

\section{Mitochondrial Dysfunction in MDD}

There is also copious evidence demonstrating that mitochondrial dysfunction plays a causative role in the pathophysiology of MDD [58, 182]. This is perhaps unsurprising given the heavy involvement of O\&NS in driving the genesis, persistence and severity of the illness and the fact that the bidirectional association between chronically elevated ROS and RNS levels and mitochondrial dysfunction has been conclusively established [13, 20, 149, 183]. The core symptoms of MDD, 
such as loss of motivation, lethargy, fatigue, neurocognitive impairment and sleep disturbances appear to be driven at least in part by dysfunction of enzyme clusters involved in the ETC [184, 185]. In addition, several authors have reported evidence indicating globally impaired bioenergetic metabolism in the brain of MDD patients, which is particularly deficient in the prefrontal cortices and the basal ganglia $[184,186]$. Other research teams have detected global abnormalities in glucose metabolism, and a reliance on glycolysis as the major source of ATP generation [185, 187, 188]. Crucially, there are also a number of studies demonstrating the existence of profound mitochondrial dysfunction in peripheral immune cells and in a range of other tissues extracted from MDD patients [189, 190]. For example, Gardner and fellow workers reported mitochondrial dysfunction notably in Complexes III and IV of the ETC leading to impaired ATP generation in the striated muscle of MDD patients complaining of physical symptoms [191]. The presence of mitochondrial dysfunction in PBMCs of MDD patients has also recently been confirmed [192]. It is also noteworthy that impaired PBMC mitochondrial respiration correlates with the severity of many core MDD symptoms, notably fatigue, loss of energy and concentration difficulties, further supporting a causative role for a shortfall in ATP production as an important driver of such symptoms [192]. A summary of the similarities and differences between MS and MDD in the area of compromised bioenergetics is provided in Table 3.

\section{Bacterial Translocation and Leaky Gut}

\section{Leaky Gut in MS}

Geffard's group has established increased IgA and IgM responses to bacterial antigens and LPS in MS patients compared with controls $[193,194]$. This indicates increased IgAand IgM-mediated immune responses to Gram-negative commensal bacteria in the peripheral blood of patients with MS. There is some evidence that this phenomenon is probably a consequence of increased gut permeability in those patients.

Table 3 Comparison of mitochondrial dysfunction between MS and MDD

\begin{tabular}{lcc}
\hline Mitochondrial dysfunction & MS & MDD \\
\hline Depleted ATP production (muscle and brain) & $\mathrm{Y}$ & $\mathrm{Y}$ \\
Decreased PCr re-synthesis following exercise & $\mathrm{Y}$ & $\mathrm{N}$ \\
Impaired oxidative phosphorylation & $\mathrm{Y}$ & $\mathrm{Y}$ \\
Acceleration of glycolysis & $\mathrm{Y}$ & $\mathrm{Y}$ \\
Damage to mitochondrial respiratory chain & $\mathrm{Y}$ & $\mathrm{Y}$ \\
Oxidative mitochondrial damage & $\mathrm{Y}$ & $\mathrm{Y}$ \\
Mitochondrial energy failure & $\mathrm{Y}$ & $\mathrm{Y}$ \\
\hline
\end{tabular}

Miyake and colleagues compared the intestinal microbiome of RRMS patients with that present in healthy participants, utilising next-generation pyrosequencing and culture-independent amplification of the bacterial $16 \mathrm{~S}$ ribosomal RNA (rRNA) gene [195]. Their subsequent analysis revealed the presence 21 species of Clostridia and Bacteroidetes in MS patients which were not present in healthy controls. Moreover, there were significant differences within Clostridia clusters XIVa and IV and Bacteroidetes between RRMS patients and controls with a relative paucity in the Clostridia species normally playing a major role in maintaining the Th17/Treg balance in the intestine [195-197].

Changes in the composition of the gut microbiome, termed gut dysbiosis, can lead to the breakdown of immune homeostasis in the intestinal immune system in turn provoking distal abnormalities in the systemic immune and inflammatory pathways and hence making a major contribution to the development of CNS diseases characterised by demyelination [198-200]. There is an accumulating body of research suggesting that the intestinal microbiota act as environmental niches where the multiple risk factors driving the development of MS merge, thereby influencing the development of disease processes [199].

Several mechanisms have been proposed which might mediate the role of gut commensals or their antigens in driving the development of MS and other diseases of the CNS, such as the activation of myelin-specific auto-aggressive Th17 lymphocytes either via molecular mimicry or bystander activation together with the production of neurotoxic metabolites or the translocation of Gram-negative commensal bacteria containing LPS into the systemic circulation as a result of increased intestinal permeability [201, 202]. In addition, several gut microbial metabolites and bacterial products may interact with the immune system to modulate CNS autoimmunity [202, 203]. Several studies have reported the presence of increased intestinal permeability in MS patients and in mice with EAE [204, 205], which would enable the translocation of LPS into the bloodstream with consequent engagement of TLR-4 and immune activation [141]. Indeed, a recent study reported that increased intestinal permeability seemed to be present at the onset of EAE, although this finding is yet to be replicated in human studies [206].

\section{Leaky Gut in MDD}

There is also considerable direct evidence of increased intestinal permeability and bacterial translocation into the systemic circulation in patients with MDD, which appears to make a significant contribution to levels of peripheral inflammation, O\&NS and autoimmunity [207, 208]. There is also accumulating evidence that variations in the composition of the microbiota are involved in the pathophysiology of major depression as well as a range of other neuroprogressive conditions 
[209, 210]. Jiang and colleagues analysed faecal samples from MDD patients in the active phase of the disease and in remission and from unaffected age- and sex-matched controls utilising pyrosequencing following polymerase chain reaction methodology [211]. These authors reported increased levels of Bacteroidetes, Actinobacteria and Proteobacteria and reduced levels of Firmicutes in patients in both illness states compared with controls. Interestingly, there was also an increase in bacterial species diversity in active MDD patients compared with controls, which was not observed in patients in remission. Furthermore, reduced levels of Faecalibacterium were observed in MDD patients, which correlated negatively with the severity of depressive symptoms [211].

The influence of the microbiota in influencing the development of MDD appears to be multifactorial. The weight of evidence suggests that one such pathway involves the modification of bidirectional communication systems between the gut and the brain. There is now a large and accumulating body of evidence demonstrating that commensal gut bacteria have the capacity to activate several neural pathways and signalling systems in the CNS and have given rise to the concept of the microbiota-gut-brain axis which relays a variety of signals between the CNS and the gastrointestinal tract $[212,213]$. While it is increasingly apparent that the optimum activity of this pathway is an essential element in maintaining intestinal and CNS homeostasis, the precise details of the mechanisms enabling such function are not fully understood although humoral, immune, neural and metabolic pathways are all considered to play a part [213, 214].

The action of translocated LPS on TLRs and the consequent activation of immune-inflammatory cascades have been discussed above and can go some way to explaining the systemically elevated levels of PICs seen in many patients with an MDD diagnosis [208]. Elevated levels of LPS can also exert a number of somewhat contradictory effects on the immune system, however, such as the activation of IDO with activation of the tryptophan catabolite (TRYCAT) pathway leading to profound immunosuppression [13]. LPS and IDO also conspire to activate Tregs, which can also lead to an immunosuppressed environment and possibly contribute to a state of T cell anergy seen in some MDD patients [215-217]. LPS activation of TLR-4 and the TRYCAT pathway in microglia, following the translocation of the antigen from the intestine, leads to a host of neuropathological consequences in animal models of depression [217, 218] and the significance of this phenomenon in the development of MDD appears to be under discussion. A summary of the similarities and differences between MS and MDD in the arena of increased intestinal permeability and bacterial translocation is provided in Table 4.

\section{Evidence from Neuroimaging Studies}

The association between structural brain abnormalities and the development of depressive symptomology in patients with MS has been the focus of intense empirical research for over two decades and there is an accumulating body of evidence suggesting that brain atrophy or demyelination in the frontal and temporal lobes are associated with the development of depression in at least some MS patients [4, 219, 220]. For example, Pujol and others detected a significant association between the presence of lesions in the white matter of the left suprainsular region and the occurrence depressive symptoms, which accounted for approximately $17 \%$ of the depression variance [221]. In a later study, the same team reported a significant association between the presence of depression and the existence of demyelinating lesions in the left arcuate fasciculus, which accounted for $26 \%$ of the depression variance as measured by the Beck Depression Inventory [222]. On the other hand, Bakshi and others reported that the presence and severity of depressive symptoms suffered by MS patients were predicted by the presence and extent of hypointense plaques on T1-weighted magnetic resonance images (black holes) in the superior parietal and frontal regions, as well as by lateral and third ventricular enlargement [223]. Zorzon and others examined $95 \mathrm{MS}$ patients, $19 \%$ of whom qualified for a diagnosis of MDD, using T1-weighted brain MRI and reported that the presence and severity of depressive symptoms were weakly correlated with right temporal brain atrophy and right frontal lesion load [224]. Moreover, the presence and magnitude of $\mathrm{T} 1$ lesions in the superior frontal and parietal regions were predictive of depression in their patients [214]. In a twoyear follow-up study, the same research team reported that increases in brain atrophy in the left frontal lobe were significantly greater in depressed MS patients than in those MS
Table 4 Similarities in gut dysfunction between MS and MDD

\begin{tabular}{lcc}
\hline Gut dysfunction & MS & MDD \\
\hline Increased IgM/IgA responses to LPS/antigens of Gram-negative bacteria & $\mathrm{Y}$ & $\mathrm{Y}$ \\
Gut dysbiosis & $\mathrm{Y}$ & $\mathrm{Y}$ \\
Leaky gut & $\mathrm{Y}$ & $\mathrm{Y}$ \\
Leaky gut mediating immune activation, inflammatory responses or autoimmunity & $\mathrm{Y}$ & $\mathrm{Y}$ \\
Possible activation of the TLR-2/4 complex & $\mathrm{Y}$ & $\mathrm{Y}$ \\
Role of gut dysbiosis, leaky gut and bacterial translocation in the pathophysiology of the illness & $\mathrm{Y}$ & $\mathrm{Y}$ \\
\hline
\end{tabular}


patients not diagnosed with depression (with a trend in the same direction for the right temporal lobe) [225]. Furthermore, these authors reported that the magnitude of atrophy displayed by patients in the right temporal lobe was a significant and independent predictor of the severity of depressive symptoms [215]. In a later cerebral MRI study, Feinstein and colleagues reported that $42 \%$ of the depression variance in their MS study cohort was accounted for by the increase in the left anterior temporal CSF volume and the increase in T2-weighted lesion volume in the left medial inferior prefrontal cortex [226].

However, while the evidence does seem to support the conclusion that structural and/or morphological changes in the frontal and temporal lobes are associated with the development of depression in at least some MS patients, many research teams in recent years have investigated potential associations between structural and/or functional abnormalities within the hippocampus and the presence of depression in individuals with MS [227, 228]. In particular, MRI studies involving patients with a confirmed diagnosis of MS have demonstrated that volume loss and abnormal morphology within the hippocampus are predictive of the presence and severity of depressive symptoms in such individuals [227-230]. This is perhaps unsurprising given that hippocampal impairment is associated with depression and with a range of cognitive abnormalities [231]. In addition, several authors have reported reduced hippocampal grey matter volume in patients with idiopathic MDD [232-234].

Significantly, while the majority of structural neuroimaging studies have revealed significant associations between the presence and or severity of depression in MS patients and various objective measures of disease burden, such as lesion load, brain atrophy and abnormalities within NAWM and NAGM; these findings have only accounted for a small percentage of the total variance of depressive symptoms in each study $[4,221,222]$. This observation suggests that these somewhat disparate findings may stem from the presence of a common underlying factor (or factors) which contributes to the pathogenesis and pathophysiology of MS and MDD [235]. This is an important point as most, if not all, these neuroimaging abnormalities are caused at least in part by neuroinflammation [236-240] and there is copious evidence that peripheral inflammation, in the guise of elevated PICs, and neuroinflammation, in the guise of activated microglia, play a causative role in the development of both illnesses as discussed above. There are also multiple lines of evidence which suggest that depressive symptoms in MS may originate as a result of synaptic impairment, derived from an abnormal production of proinflammatory molecules by activated microglia during central inflammation [166, 241, 242].

From the perspective of data demonstrating an association between hippocampal atrophy and the development of depression in MS patients, it is also noteworthy that the existence of microglial activation and other aspects of hippocampal pathology such as neuronal loss, atrophy and extensive demyelination, in at least some MS patients, has been confirmed by neuroimaging and post mortem studies in between 53 and $79 \%$ of patients recruited into studies [243-245]. In addition, among the various CNS sites involved in MS, the hippocampus is particularly vulnerable to the detrimental effects of neuroinflammation, largely because of the high density of IL-1 receptors found in that region of the brain $[243,246]$. Furthermore, strong evidence confirming the presence of neuroinflammation-induced abnormalities in the hippocampus and the development of depressive symptoms in MS patients have been provided by two recent studies conducted by Rocca and fellow workers and Cosalanti and fellow workers [235, 247]. In their structural MRI and resting-state (RS) functional MRI (fMRI) study of 69 MS patients, Rocca and coworkers demonstrated a strong correlation between, on the one hand, reduced hippocampal RS functional connectivity (FC) with cortical-subcortical regions of the default-mode network and, on the other hand, increased T2-weighted lesion volume, duration of the disease, and the severity of clinical disability and depressive symptomatology [236]. These findings were supported by Cosalanti and fellow workers who utilised RS fMRI and positron emission tomography (PET) to investigate a potential relationship between the existence of neuroinflammation, hippocampal FC and the existence of depression in MS patients [224]. Importantly, these authors reported that the intensity of microglial activation, indexed by the second-generation $18-\mathrm{kDa}$ translocator protein (TSPO) radioligand $\left[{ }^{18} \mathrm{~F}\right] \mathrm{BRIII}$, within the hippocampus, was positively correlated with the severity of depression, indexed by the Beck Depression Inventory, while there was also a positive correlation between the hippocampal $\left[{ }^{18} \mathrm{~F}\right] \mathrm{BR}$ III distribution volume ratio and the strength of hippocampal FC with prefrontal, parietal and occipital cortices [224].

\section{Neuroendocrine Abnormalities}

\section{Cortisol Levels and Cortisol Awakening Response in MS}

Elevated basal levels of plasma cortisol and adrenocorticotropic hormone (ACTH), together with enlarged adrenal (suprarenal) glands, have been observed in RRMS patients [248-250]. Moreover, large increases in cortisol levels have been observed in proximity to or during acute relapse characterised by a significant increase in inflammatory state [251-253]. Unsurprisingly, the increased levels of inflammatory markers in the CSF seen in patients during this phase of the illness is associated with an increase in hypothalamicpituitary-adrenal (HPA) axis activity and a corresponding increase in the numbers of patients reporting symptoms of 
depression [254]. This association between increased HPA axis activity, elevated cortisol secretion and increase in inflammation may well be significant from the perspective of the pathophysiology of the illness, as increased HPA axis dysregulation in RRMS is associated with global neurodegeneration and an aggressive disease profile [255]. It is also noteworthy that basal levels of cortisol and levels of cortisol following corticotropin-releasing hormone (CRH) stimulation vary according to disease subtypes and severity of MS for reasons which are not fully understood [256]. However, one factor may be the levels and activity of $\mathrm{CRH}$-secreting neurones in the hypothalamus, as increased numbers and activity of such neurones have been detected in this region of the brain in RRMS patients post mortem, possibly resulting from an upregulation in an attempt to mitigate against the presence of inflammation [252, 257]. However in severe disease, increased inflammatory lesion burden in the hypothalamus leads to reduced numbers and activity of CRH neurones and a denuded production of cortisol and thus, at least potentially, an impaired capacity to combat inflammation [258].

Several authors have investigated potential relationships between various measures of HPA axis activity and cortisol levels and the presence of depression in MS patients. For example, Gold and fellow workers reported significantly increased levels of evening cortisol in RRMS patients with depression but normal levels in patients without such symptoms compared with healthy controls [227, 259]. Similarly, Kern and others reported that elevated cortisol awakening response (CAR) levels were only observed in RRMS patients reporting symptoms of depression and noted a significant association between CAR levels and the extent of neurological disability and the presence of depression [260]. Kern and others also reported a significant association between elevated CAR values and increases in disease severity, indexed by the EDSS [261]. Briefly, these authors investigated the longitudinal relationship between CAR, extent of neurological disability as measured by EDSS and the presence of depressive symptoms in 77 MS patients over a nine-month period [261]. They noted that RRMS patients with increases in neurological disability over the relevant time-period displayed a significantly greater CAR compared with healthy participants while CAR levels in patients whose EDSS scores remained stable were not significantly different from healthy controls. This is of interest given data demonstrating an association between increased EDSS scores and increased levels of inflammatory markers and an association between increased HPA axis activity during relapse and the advent of MDD $[254,262]$. However, in a departure from earlier findings by this research team, CAR values were not associated with the presence of depressive symptoms in this study nor indeed with an index of patient stress, but baseline values of EDSS and CAR were predictive of EDSS at the nine-month follow-up [250]. This latter finding is consistent with other lines of evidence which indicate that HPA axis abnormalities are associated with more severe MS and possibly even an enhanced susceptibility to developing the disease [242, 243, 247]. HPA axis hyperactivity in particular is associated with advancing disease and global neurodegeneration, possibly as a result of increases in cortisol production which may cause widespread damage in several areas of the brain such as the hypothalamus, which may go some way to explaining the associations between CAR and disease severity and/or progression and the development of MDD in patients with more aggressive disease $[217,245]$.

\section{Cortisol and CAR Abnormalities in MDD}

The data regarding CAR levels in MDD are at first sight somewhat inconsistent with authors reporting elevated, lowered and normal CAR values in their study cohorts compared with healthy controls [263]. For example, Vreeberg and fellow workers reported an increased CAR in a large cohort of currently depressed middle-aged females and middle-aged females in remission [264]. Similar associations have been reported in adolescent and young adult females [265, 266]. Several other research teams have also reported elevated CAR values in medication-free patients in remission, which indicates that HPA axis dysfunction may be a trait in some individuals which confers a vulnerability to developing MDD [264, 267-269]. However, other research teams have reported a blunted CAR in young adult women and older individuals with relatively mild or moderate clinical depression [270] and a significantly reduced CAR in patients with severe depression [271]. These findings have been echoed in several other studies with patients with relatively moderate symptoms displaying an elevated CAR while patients with more severe symptoms almost invariably showing a decreased CAR both in cross-sectional and longitudinal studies [272, 273]. The reduced CAR in severe depression indicates HPA axis hypofunction possibly as a result of CRH receptor downregulation as a result of chronically elevated levels of PICs rather than the reduced numbers and activity of CRH neurones [264] seen in severe RRMS [258].

\section{Glucocorticoid Receptor Resistance in MS}

There is accumulating evidence, largely from cross-sectional studies, that glucocorticoid (GC) receptor (GR) sensitivity, as determined by proliferation of T cells and PIC production, is significantly impaired in RRMS patients compared with healthy age- and sex-matched control subjects [274, 275]. This phenomenon is of importance as the activity of these receptors mediates the response of corticosteroids released by HPA axis activation and is essentially the effector of the neuroendocrine anti-inflammatory response (reviewed [276]). This is clinically significant as GR resistance is associated 
with non-responsiveness to corticosteroid therapy used in an attempt to reduce the time spent in relapse [277, 278] (reviewed in [279]).

Perhaps unsurprisingly, several polymorphisms affecting GR sensitivity, such as N363S, ER22/23EK and $B c l 1 \mathrm{C} / \mathrm{G}$, have been associated with more aggressive MS as assessed by EDSS and MRI [280, 281]. However, a recent larger, multi-ethnic study found no association between the presence of these polymorphisms and illness severity and that nongenetic factors such as the presence of inflammation and elevated PICs were the most important cause of GC resistance in RRMS patients [282]. This conclusion is supported by other lines of evidence which indicate that the GC sensitivity of T cells can be modulated by PICs and other inflammatory molecules [283-285]. There are also data suggesting that GC resistance is more pronounced during relapse than during remission $[252,286]$.

\section{GR Resistance in MDD}

The weight of evidence suggests that GR resistance and abnormalities in GR functioning occur in approximately $80 \%$ of MDD patients and are held to be the most reproducible biological measures associated with the illness [287-289]. These are important findings as there is accumulating evidence that PIC- and/or p38 MAPK-induced GR resistance may be a major driver of the increased inflammatory response system observed in many MDD patients which in turn is responsible for HPA axis hyperactivity seen in many individuals afforded this diagnosis [290-292]. This phenomenon has important implications from a treatment perspective, as GR resistance secondary to increased inflammation is associated with resistance to antidepressants, and there is some evidence that GR resistance must be overcome before a patient enters remission [278, 280, 281] The significance of GR resistance is further emphasised by the presence of data demonstrating a significant association between the development of GR resistance in patients and the advent of depressive symptoms [293]. Chronic stress and the resultant upregulation of inflammatory pathways as part of the conserved transcriptional response to adversity also appear to be causes of GR resistance [294, 295]. This is of interest as this stress-induced inflammatory response in combination with diminished GR responsiveness is considered to underpin the pathogenesis of MDD [296]. Moreover, the conserved transcriptional response to physical adversity is also activated by a range of perceived non-physical or symbolic threats which in part depend on within-patient factors [285]. These are intriguing observations as they allow for a contribution from psychosocial factors to the inflammatory burden of an individual MS patient and possibly to the severity of the disease experienced and indeed to the existence, or otherwise, of depressive symptoms. Finally, impaired GR function makes effector $\mathrm{T}$ cells resistant to chemokine-induced recruitment into the CNS [297]. This is of importance as T lymphocyte recruitment into the CNS plays an important role in maintaining cognitive function, neurogenesis and synaptic plasticity in an environment of neuroinflammation $[298,299]$ and thus GR resistance may contribute to the severe cognitive dysfunction and impaired neurogenesis seen in many people afforded a diagnosis of MDD.

\section{Therapeutic Implications}

\section{Desipramine}

Given the arguments made in this paper, it would seem reasonable to propose that a molecule which has antidepressant, antioxidant and anti-inflammatory actions might have therapeutic actions in MS. Desipramine, which is an active metabolite of the tricyclic antidepressants imipramine and lofepramine, is such a molecule.

The antidepressant activity of desipramine, which inhibits the central reuptake of noradrenaline (norepinephrine) and, to a lesser extent, serotonin, has been well established since the mid-1960s [300, 301]. The combined plasma concentrations of desipramine, which is a demethylated metabolite of the "gold standard" tricyclic antidepressant imipramine, and is also known as desmethylimipramine (formally, 10,11dihydro-5-[3-(methylamino)propyl]-5H-dibenz[b,f]azepine monohydrochloride), and imipramine have been found to show an approximately linear relationship with clinical antidepressant response, at doses higher than a minimal plasma threshold below which such improvement is not seen [302-305]. Indeed, it has been suggested that the parent antidepressants imipramine and lofepramine act as prodrugs of desipramine [305].

The antioxidant and anti-inflammatory actions of desipramine (unlike imipramine) are also well established, with a number of studies demonstrating its protective effects against oxidative stress. Desipramine has been shown to have antioxidant and anti-inflammatory actions in experimentally induced colitis in rats, with the drug attenuating the severity and extent of tissue damage, reducing myeloperoxidase activity (in a dose-dependent way), increasing the level of reduced glutathione in colonic tissue and diminishing PIC levels [306]. In olfactory-bulbectomised rats, desipramine has been shown to reverse the usual depressed neutrophil phagocytosis associated with this operation, to shorten the time to the start of phagocytosis, and to reverse the decreased activity of glutathione peroxidase [307]. In a murine model of chronic fatigue syndrome (myalgic encephalomyelitis), desipramine has been found to attenuate oxidative stress, as well as decreasing the immobility time, increasing locomotor activity and diminishing anxiety; in particular, there was a dosedependent increase in reduced glutathione, a dose-dependent 
increase in catalase, and a dose-dependent reduction in nitrite levels [308]. Similarly, desipramine has been shown to attenuate oxidative damage and to restore mitochondrial enzyme activities, including of Complexes I, II and IV of the ETC, in a murine ischaemia/reperfusion injury model of transient global ischemia [309]. Similarly, desipramine has been shown to have antioxidant and anti-inflammatory actions in a murine model of carrageenan-induced inflammation [310].

Given the importance of HPA axis and hippocampal functioning in MS, described earlier, it is germane to mention a controlled murine study by Bravo and colleagues in which the effects of chronic stress were studied [311]. Chronic stress was associated with increased body mass, which was prevented by desipramine; a large increase in serum corticosterone levels, which was prevented by desipramine; anhedonic behaviour, prevented by desipramine; increases in measures of learned helplessness, prevented by desipramine; and increased immobility, which was significantly reduced by desipramine [305]. It has been hypothesised that phosphorylation of extracellular signal-regulated kinase (ERK)1/2 might mediate antidepressant action; in this study, hippocampal levels of phosphoERK1/2 (P-ERK1/2) were assayed and indeed the ratios of P-ERK1/ERK1 and P-ERK2/ERK2 were found to be elevated in the group of rats exposed to chronic stress, but this effect was reversed by desipramine [305]. Finally, chronic stress and GCs have been associated with decreased expression of brainderived neurotrophic factor (BDNF) [312]. In the study by Bravo and colleagues, chronic stress was indeed associated with a reduction in BDNF mRNA and this was prevented in the CA3 hippocampal region by desipramine [305]. Thus, there is good evidence that desipramine has neuroprotective actions, including in the hippocampus.

\section{Clinical Trial}

While desipramine is not available for oral administration, its parent prodrugs lofepramine and imipramine are readily available in such a formulation (although, at the time of writing, lofepramine is not available in certain countries, including the United States of America and Australia). In 1996, the late Cari Loder, who herself suffered from MS, published a book describing the possibility, based on her serendipitous experience, that MS symptoms might improve with treatment using lofepramine, L-phenylalanine and vitamin $\mathrm{B}_{12}$ [313]. A randomised, placebo-controlled, double-blind trial of this combination subsequently took place in the United Kingdom; the lofepramine-based treatment was indeed found to be effective in relieving MS symptoms, with benefits being noted within a fortnight to a month [313, 314]. The improvement was statistically significant but the authors of the study cautioned that the improvement was clinically small and that further research was needed to confirm and explore its significance [314].
No further clinical trials in MS involving lofepramine have taken place. However, a subgroup of the MS patients taking part in the above study underwent MRI scanning of the brain by Puri and colleagues at baseline and six-month follow-up. Using a highly accurate method for quantifying changes in ventricular volume (an index of cerebral atrophy) developed by the same group [315], it was found that the mean lateral ventricular volume increased far less in the treated group than in the untreated one; moreover, in the treated group the ventricular size change correlated with changes in Gulick MSrelated symptoms scale scores and Gulick MS-related activities of daily living scale scores [316]. Furthermore, in the treated group, there was a significant reduction in the number of focal lesions on the T1-weighted scans [316].

\section{Summary and Conclusion}

Elevated O\&NS and compromised antioxidant defences in the periphery and CNS are strongly implicated as a causative element in the pathophysiology of MS and MDD. Evidence of a causative role includes an established correlation between levels of oxidative stress and number of relapses and increases in levels of O\&NS prior to relapse in MS and correlation between O\&NS levels and severity of illness in MDD.

Imbalances in the production of pro- and anti-inflammatory cytokines are seen in the serum and CNS of both illnesses and it is noteworthy that the concentrations of one or more cytokines correlate with the severity of both illnesses along several different dimensions. For example, levels of TNF $\alpha$ in the periphery are predictive of relapse and correlate with disability and fatigue, while levels of IL-1 are predictive of a poor prognosis and cortical lesion load. It is also noteworthy that peripheral levels of IL-6 and CRP differentiate MS patients with depression from those free of depression. This is perhaps unsurprising as levels of peripheral inflammation correlate with the severity and chronicity of MDD. The presence of abnormally high levels of IL-17 in the periphery and CNS would appear to clearly differentiate patients with MS from those with a diagnosis of MDD. This highly inflammatory and tissue-damaging cytokine is generally produced by activated Th17 T cells and to a lesser extent B cells and intestinal dendritic cells and these differences in cytokine population between the two illnesses might be a reflection of the fact that the source of cytokine production in MDD patients appears to be M1-polarised macrophages, neutrophils, anergised T cells and the NLP-3 inflammasome while cytokine production in MS is primarily driven by activated Th1 and Th17 lymphocytes and effector B cells, although recent evidence suggests DAMP-mediated inflammasome activation in this illness as well.

Given the presence of excessive inflammation and oxidative stress, the presence of widespread mitochondrial 
dysfunction in the brain and periphery of sufferers of both illnesses is unsurprising. The nature of mitochondrial dysfunction largely confined to enzymes of the ETC is also very similar in MS and MDD patients. This is strongly suggestive of the detrimental effects of chronically elevated NO and peroxynitrite. It does seem likely that mitochondrial dysfunction does make an independent contribution to the pathophysiology of both illnesses both as a result of ATP depletion and increased production of ROS. The exact origin of chronic O\&NS, immune-inflammation and mitochondrial dysfunction are very difficult to determine given their complex interrelationship but, once commenced, established biochemical relationships predict the development of a self-amplifying pathology. This may well be a reason why simple antioxidants have met with limited success as treatment options while preparations targeting mechanisms driving the generation of oxidative stress, inflammation and mitochondrial dysfunction appear to be more promising.

There is now a considerable body of evidence demonstrating abnormalities in microglial activation and/or function in MS and MDD. Microglia can be activated as a result of chronic peripheral inflammation and activation of these glial cells plays a major role in the pathogenesis and the pathophysiology of MS largely as a source of cytokines, O\&NS, inflammatory mediators and neurotoxic TRYCATs. The neurotoxicity and polarisation pattern of microglia in MS are heavily determined by bidirectional interactions between activated encephalogenic Th17 T cells from the periphery which is not a feature in MDD patients. Epigenetic dysregulation in terms of abnormal histone acetylation and miRNA production is clearly an element in the pathology induced by microglia and the extreme neurotoxicity of Th17 T cells seen in MS which once again does not seem to be the case in MDD. The source of Th17 T cell activation in MS is not fully understood but may result from inflammation-induced dysbiosis and breakdown of intestinal homeostasis. The nature of microglial pathology in MDD appears to be different from that seen in MS and would appear to involve the impaired function of many of their CNS housekeeping roles such as maintaining synaptic plasticity, learning memory and other aspects of cognitive functioning.

Increased inflammation could underpin the increased BBB permeability, intestinal permeability and bacterial translocation seen in MDD. While increased intestinal permeability can be a cause of dysbiosis; the quite distinct patterns of dysbiosis seen in MS and MDD indicate another origin for these observations. The advent of depressive symptoms in MS appears to be associated with the levels of brain atrophy and demyelination in NAWM and NAGM in the frontal and temporal lobes, indicating that such symptomatology is a consequence of disease process. The relationship between altered morphology, reduced volume and lesions in the hippocampus caused by inflammatory mediators released by activated microglia and the development of depressive symptoms would also support such a conclusion. However several lines of research also indicate that psychosocial factors could make a contribution to the pathogenesis of depressive symptoms in MS, most likely by increasing the level of peripheral inflammation and subsequent neuroinflammation.

Theoretically, the antidepressant lofepramine and, in particular, its active metabolite desipramine, may be beneficial not only for the depressive symptomatology but also for the neurological symptoms in MS. One clinical trial has been carried out thus far with, in particular, promising MRI findings.

In conclusion, multiple lines of evidence suggest that many abnormalities common to MS and MDD likely have their origins in the presence of chronic inflammation and concomitant oxidative stress and individual differences could be a product of disparate genetic, epigenetic and environmental influences. However, when the evidence is considered as a whole, the view that MDD exists as an entirely separate nosological entity from "MS-associated MDD", which is associated with a characteristic array of empirical abnormalities, would appear to be reasonable.

Acknowledgements MB is supported by a National Health and Medical Research Council (NHMRC) Senior Principal Research Fellowship (grant number 1059660).

Open Access This article is distributed under the terms of the Creative Commons Attribution 4.0 International License (http:// creativecommons.org/licenses/by/4.0/), which permits unrestricted use, distribution, and reproduction in any medium, provided you give appropriate credit to the original author(s) and the source, provide a link to the Creative Commons license, and indicate if changes were made.

\section{References}

1. Moll NM, Rietsch AM, Thomas S, Ransohoff AJ, Lee J-C, Fox R, Chang A, Ransohoff RM et al (2011) Multiple sclerosis normalappearing white matter: pathology-imaging correlations. Ann Neurol 70(5):764-773. https://doi.org/10.1002/ana.22521

2. Naegele M, Martin R (2014) The good and the bad of neuroinflammation in multiple sclerosis. Handb Clin Neurol 122:59-87. https://doi.org/10.1016/b978-0-444-52001-2.00003-0

3. Zindler E, Zipp F (2010) Neuronal injury in chronic CNS inflammation. Best Pract Res Clin Anaesthesiol 24(4):551-562. https:// doi.org/10.1016/j.bpa.2010.11.001

4. Feinstein A, Magalhaes S, Richard J-F, Audet B, Moore C (2014) The link between multiple sclerosis and depression. Nat Rev Neurol 10(9):507-517. https://doi.org/10.1038/nrneurol.2014.139

5. Marrie RA, Miller A, Sormani MP, Thompson A, Waubant E, Trojano M, O'Connor P, Fiest K et al (2016) Recommendations for observational studies of comorbidity in multiple sclerosis. Neurology 86(15):1446-1453. https://doi.org/10.1212/wnl. 0000000000002474

6. Marrie RA, Cohen J, Stuve O, Trojano M, Sørensen PS, Reingold S, Cutter G, Reider N (2015) A systematic review of the incidence and prevalence of comorbidity in multiple sclerosis: overview. 
Mult Scler (Houndmills, Basingstoke, England) 21(3):263-281. https://doi.org/10.1177/1352458514564491

7. Wishart H, Sharpe D (1997) Neuropsychological aspects of multiple sclerosis: a quantitative review. J Clin Exp Neuropsychol 19(6):810-824. https://doi.org/10.1080/01688639708403762

8. Prakash RS, Snook EM, Lewis JM, Motl RW, Kramer AF (2008) Cognitive impairments in relapsing-remitting multiple sclerosis: a meta-analysis. Mult Scler (Houndmills, Basingstoke, England) 14(9):1250-1261. https://doi.org/10.1177/1352458508095004

9. Bobholz JA, Rao SM (2003) Cognitive dysfunction in multiple sclerosis: a review of recent developments. Curr Opin Neurol 16(3):283-288. https://doi.org/10.1097/01.wco.0000073928. 19076.84

10. Arnett PA, Higginson CI, Randolph JJ (2001) Depression in multiple sclerosis: relationship to planning ability. J Int Neuropsychol Soc : JINS 7(6):665-674

11. Niino M, Mifune N, Kohriyama T, Mori M, Ohashi T, Kawachi I, Shimizu Y, Fukaura H et al (2014) Apathy/depression, but not subjective fatigue, is related with cognitive dysfunction in patients with multiple sclerosis. BMC Neurol 14:3. https://doi.org/10. 1186/1471-2377-14-3

12. Feinstein A, Pavisian B (2017) Multiple sclerosis and suicide. Mult Scler J 23(7):923-927. https://doi.org/10.1177/ 1352458517702553

13. Maes M (2011) Depression is an inflammatory disease, but cellmediated immune activation is the key component of depression. Prog Neuropsychopharmacol Biol Psychiatry 35:664-675

14. Kessler RC, Bromet EJ (2013) The epidemiology of depression across cultures. Annu Rev Public Health 34:119-138. https://doi. org/10.1146/annurev-publhealth-031912-114409

15. Feinstein A (2011) Multiple sclerosis and depression. Mult Scler 17(11):1276-1281. https://doi.org/10.1177/1352458511417835

16. Hurley LL, Tizabi Y (2013) Neuroinflammation, Neurodegeneration and Depression. Neurotox Res 23(2):131144. https://doi.org/10.1007/s12640-012-9348-1

17. Maes M, Berk M, Goehler L, Song C, Anderson G, Galecki P (2012) Depression and sickness behavior are Janus-faced responses to shared inflammatory pathways. BMC Med 10:66

18. Morris G, Berk M, Walder K, Maes M (2015) Central pathways causing fatigue in neuro-inflammatory and autoimmune illnesses. BMC Med 13(1):28

19. Morris G, Anderson G, Galecki P, Berk M, Maes M (2013) A narrative review on the similarities and dissimilarities between myalgic encephalomyelitis/chronic fatigue syndrome (ME/CFS) and sickness behavior. BMC Med 11:64

20. Morris G, Berk M (2015) The many roads to mitochondrial dysfunction in neuroimmune and neuropsychiatric disorders. BMC Med 13(1):68

21. Kallaur AP, Lopes J, Oliveira SR, Simão ANC, Reiche EMV, Almeida ERD, Morimoto HK, Pereira WLCJ, Alfieri DF, Borelli SD, Kaimen-Maciel DR, Maes M (2015) Immuneinflammatory and oxidative and nitrosative stress biomarkers of depression symptoms in subjects with multiple sclerosis: increased peripheral inflammation but less acute neuroinflammation. Mol Neurobiol:1-12. https://doi.org/10.1007/s12035-0159443-4

22. Moylan S, Berk M, Dean O, Samuni Y, Williams L, O'Neil A (2014) Oxidative \& nitrosative stress in depression: why so much stress? Neurosci Biobehav Rev 45C:46-62

23. Rodríguez-Martín E, Picón C, Costa-Frossard L, Alenda R, Sainz de la Maza S, Roldán E, Espiño M, Villar LM et al (2015) Natural killer cell subsets in cerebrospinal fluid of patients with multiple sclerosis. Clin Exp Immunol 180(2):243-249. https://doi.org/10. 1111/cei.12580

24. Maes M, Lambrechts J, Suy E, Vandervorst C, Bosmans E (1994) Absolute number and percentage of circulating natural killer, non-
MHC-restricted T cytotoxic, and phagocytic cells in unipolar depression. Neuropsychobiology 29(4):157-163

25. Costantino C, Baecher-Allan C, Hafler D (2008) Multiple sclerosis and regulatory T cells. J Clin Immunol 28:697-706

26. Savitz J, Tan T, Taylor A, Drevets W, Teague K (2013) Abnormalities in regulatory T cells and natural killer cells in major depressive disorder. J Immunol 190:43.25

27. Felger JC, Lotrich FE (2013) Inflammatory cytokines in depression: neurobiological mechanisms and therapeutic implications. Neuroscience 246:199-229. https://doi.org/10.1016/j. neuroscience.2013.04.060

28. Miller A (2010) Depression and immunity: a role for T cells? Brain Behav Immun 24:1-8

29. Hartmann FJ, Khademi M, Aram J, Ammann S, Kockum I, Constantinescu C, Gran B, Piehl F et al (2014) Multiple sclerosis-associated IL2RA polymorphism controls GM-CSF production in human TH cells. Nat Commun 5:5056. https://doi.org/ 10.1038/ncomms6056

30. Sun Y, Li Q, Gui H, Xu D-P, Yang Y-L, Su D-F, Liu X (2013) MicroRNA-124 mediates the cholinergic anti-inflammatory action through inhibiting the production of pro-inflammatory cytokines. Cell Res 23(11):1270-1283. https://doi.org/10.1038/cr. 2013.116

31. Kucukali CI, Kurtuncu M, Coban A, Cebi M, Tuzun E (2015) Epigenetics of multiple sclerosis: an updated review. Neuromolecular Med 17(2):83-96. https://doi.org/10.1007/ s12017-014-8298-6

32. Goldberg D (2011) The heterogeneity of "major depression". World Psychiatry 10(3):226-228

33. Sato F, Martinez NE, Omura S, Tsunoda I (2011) Heterogeneity versus homogeneity of multiple sclerosis. Expert Rev Clin Immunol 7(2):165-167. https://doi.org/10.1586/eci.11.3

34. Spencer JI, Bell JS, DeLuca GC (2017) Vascular pathology in multiple sclerosis: reframing pathogenesis around the bloodbrain barrier. J Neurol Neurosurg Psychiatry. https://doi.org/10. 1136/jnnp-2017-316011

35. Gironi M, Borgiani B, Mariani E, Cursano C, Mendozzi L, Cavarretta R (2014) Oxidative stress is differentially present in multiple sclerosis courses, early evident, and unrelated to treatment. J Immunol Res 2014:961863

36. Fiorini A, Koudriavtseva T, Bucaj E, Coccia R, Foppoli C, Giorgi A (2013) Involvement of oxidative stress in occurrence of relapses in multiple sclerosis: the spectrum of oxidatively modified serum proteins detected by proteomics and redox proteomics analysis. PloS one 8:e65184

37. Oliveira S, Kallaur A, Simao A, Morimoto H, Lopes J, Panis C (2012) Oxidative stress in multiple sclerosis patients in clinical remission: association with the expanded disability status scale. $\mathrm{J}$ Neurol Sci 321:49-53

38. Rejdak K, Leary S, Petzold A, Thompson A, Miller D, Giovannoni G (2010) Urinary neopterin and nitric oxide metabolites as markers of interferon beta-1a activity in primary progressive multiple sclerosis. Mult Scler 16:1066-1072

39. Tasset I, Aguera E, Sanchez-Lopez F, Feijoo M, Giraldo A, Cruz A (2012) Peripheral oxidative stress in relapsing-remitting multiple sclerosis. Clin Biochem 45:440-444

40. Tasset I, Bahamonde C, Aguera E, Conde C, Cruz A, PerezHerrera A (2013) Effect of natalizumab on oxidative damage biomarkers in relapsing-remitting multiple sclerosis. Pharmacol Rep 65:624-631

41. Ortiz G, Pacheco-Moises F, Bitzer-Quintero O, RamirezAnguiano A, Flores-Alvarado L, Ramirez-Ramirez V (2013) Immunology and oxidative stress in multiple sclerosis: clinical and basic approach. Clin Dev Immunol 2013:708659

42. Bizzozero O, DeJesus G, Callahan K, Pastuszyn A (2005) Elevated protein carbonylation in the brain white matter and gray 
matter of patients with multiple sclerosis. J Neurosci Res 81:687695

43. Miller E, Walczak A, Saluk J, Ponczek M, Majsterek I (2012) Oxidative modification of patient's plasma proteins and its role in pathogenesis of multiple sclerosis. Clin Biochem 45:26-30

44. Calabrese V, Scapagnini G, Ravagna A, Bella R, Foresti R, Bates $T$ (2002) Nitric oxide synthase is present in the cerebrospinal fluid of patients with active multiple sclerosis and is associated with increases in cerebrospinal fluid protein nitrotyrosine and Snitrosothiols and with changes in glutathione levels. J Neurosci Res 70:580-587

45. Mattsson N, Haghighi S, Andersen O, Yao Y, Rosengren L, Blennow K (2007) Elevated cerebrospinal fluid F2-isoprostane levels indicating oxidative stress in healthy siblings of multiple sclerosis patients. Neurosci Lett 414:233-236

46. Giovannoni G, Heales S, Land J, Thompson E (1998) The potential role of nitric oxide in multiple sclerosis. Mult Scler 4:212-216

47. Jack C, Antel J, Bruck W, Kuhlmann T (2007) Contrasting potential of nitric oxide and peroxynitrite to mediate oligodendrocyte injury in multiple sclerosis. Glia 55:926-934

48. Maes M, Fisar Z, Medina M, Scapagnini G, Nowak G, Berk M (2012) New drug targets in depression: inflammatory, cellmediated immune, oxidative and nitrosative stress, mitochondrial, antioxidant, and neuroprogressive pathways. And new drug candidates-Nrf2 activators and GSK-3 inhibitors. Inflammopharmacology 20:127-150

49. Maes M, Mihaylova I, Kubera M, Leunis JC, Geffard M (2011) IgM-mediated autoimmune responses directed against multiple neoepitopes in depression: new pathways that underpin the inflammatory and neuroprogressive pathophysiology. J Affect Disord 135(1-3):414-418. https://doi.org/10.1016/j.jad.2011.08. 023

50. Anderson G, Berk M, Dean O, Moylan S, Maes M (2014) Role of immune-inflammatory and oxidative and nitrosative stress pathways in the etiology of depression: therapeutic implications. CNS Drugs 28(1):1-10. https://doi.org/10.1007/s40263-013-0119-1

51. Galecki P, Szemraj J, Bienkiewicz M, Florkowski A, Galecka E (2009) Lipid peroxidation and antioxidant protection in patients during acute depressive episodes and in remission after fluoxetine treatment. Pharmacol Rep : PR 61(3):436-447

52. Forlenza M, Miller G (2006) Increased serum levels of 8-hydroxy2'-deoxyguanosine in clinical depression. Psychosom Med 68:1-7

53. Czarny P, Kwiatkowski D, Kacperska D, Kawczynska D, Talarowska M, Orzechowska A, Bielecka-Kowalska A, Szemraj $\mathrm{J}$ et al (2015) Elevated level of DNA damage and impaired repair of oxidative DNA damage in patients with recurrent depressive disorder. Med Sci Monit 21:412-418. https://doi.org/10.12659/ msm. 892317

54. Maes M, De Vos N, Pioli R, Demedts P, Wauters A, Neels H (2000) Lower serum vitamin E concentrations in major depression. Another marker of lowered antioxidant defenses in that illness. J Affect Disord 58:241-246

55. Milaneschi Y, Cesari M, Simonsick E, Vogelzangs N, Kanaya A, Yaffe K (2013) Lipid peroxidation and depressed mood in community-dwelling older men and women. Plos ONE 8:e65406

56. Tsuboi H, Shimoi K, Kinae N, Oguni I, Hori R, Kobayashi F (2004) Depressive symptoms are independently correlated with lipid peroxidation in a female population: comparison with vitamins and carotenoids. J Psychosom Res 56:53-58

57. Yager S, Forlenza M, Miller G (2010) Depression and oxidative damage to lipids. Psychoneuroendocrinology 35:1356-1362

58. Morris G, Berk M, Galecki P, Walder K, Maes M (2015) The neuro-immune pathophysiology of central and peripheral fatigue in systemic immune-inflammatory and neuro-immune diseases. Mol Neurobiol 53(2):1195-1219. https://doi.org/10.1007/ s12035-015-9090-9
59. Berk M, Dean O, Cotton S, Jeavons S, Tanious M, Kohlmann K (2014) The efficacy of adjunctive $\mathrm{N}$-acetylcysteine in major depressive disorder: a double-blind, randomized, placebo-controlled trial. J Clin Psychiatry 75:628-636

60. Dean O, Maes M, Ashton M, Berk L, Kanchanatawan B, Sughondhabirom A (2014) Protocol and rationale-the efficacy of minocycline as an adjunctive treatment for major depressive disorder: a double blind, randomised. Placebo Controlled Trial. Clin Psychopharmacol Neurosci 12:180-188

61. Maes M, Kubera M, Mihaylova I, Geffard M, Galecki P, Leunis JC, Berk M (2013) Increased autoimmune responses against autoepitopes modified by oxidative and nitrosative damage in depression: implications for the pathways to chronic depression and neuroprogression. J Affect Disord 149(1-3):23-29. https://doi. org/10.1016/j.jad.2012.06.039

62. Nunes S, Vargas H, Prado E, Barbosa D, de Melo L, Moylan S (2013) The shared role of oxidative stress and inflammation in major depressive disorder and nicotine dependence. Neurosci Biobehav Rev 37:1336-1345

63. Tobe E (2013) Mitochondrial dysfunction, oxidative stress, and major depressive disorder. Neuropsychiatr Dis Treat 9:567-573

64. Anglin R, Rosebush P, Mazurek M, Tarnopolsky M, Noseworthy $M$ (2011) The psychiatric manifestations of mitochondrial cytopathies: a clinical and MR spectroscopy investigation. Mitochondrion 11:639-640

65. Hadžović-Džuvo A, Lepara O, Valjevac A, Avdagić N, Hasić S, Kiseljaković E, Ibragić S, Alajbegović A (2011) Serum total antioxidant capacity in patients with multiple sclerosis. Bosnian J Basic Med Sci 11(1):33-36

66. Besler HT, Comoglu S, Okcu Z (2002) Serum levels of antioxidant vitamins and lipid peroxidation in multiple sclerosis. Nutr Neurosci 5(3):215-220. https://doi.org/10.1080/ 10284150290029205

67. Toncev G, Milicic B, Toncev S, Samardzic G (2002) Serum uric acid levels in multiple sclerosis patients correlate with activity of disease and blood-brain barrier dysfunction. Eur J Neurol 9(3): 221-226

68. Carvalho AN, Lim JL, Nijland PG, Witte ME, Van Horssen J (2014) Glutathione in multiple sclerosis: more than just an antioxidant? Mult Scler 20(11):1425-1431. https://doi.org/10.1177/ 1352458514533400

69. Ferreira B, Mendes F, Osorio N, Caseiro A, Gabriel A, Valado A (2013) Glutathione in multiple sclerosis. Br J Biomed Sci 70(2): 75-79

70. Pennisi G, Cornelius C, Cavallaro MM, Salinaro AT, Cambria MT, Pennisi M, Bella R, Milone P et al (2011) Redox regulation of cellular stress response in multiple sclerosis. Biochem Pharmacol 82(10):1490-1499. https://doi.org/10.1016/j.bcp. 2011.07.092

71. Gray E, Kemp K, Hares K, Redondo J, Rice C, Scolding N, Wilkins A (2014) Increased microglial catalase activity in multiple sclerosis grey matter. Brain Res 1559:55-64. https://doi.org/10. 1016/j.brainres.2014.02.042

72. van Horssen J, Schreibelt G, Drexhage J, Hazes T, Dijkstra CD, van der Valk P, de Vries HE (2008) Severe oxidative damage in multiple sclerosis lesions coincides with enhanced antioxidant enzyme expression. Free Radic Biol Med 45(12):1729-1737. https:// doi.org/10.1016/j.freeradbiomed.2008.09.023

73. Emamgholipour S, Hossein-Nezhad A, Sahraian MA, Askarisadr F, Ansari M (2016) Evidence for possible role of melatonin in reducing oxidative stress in multiple sclerosis through its effect on SIRT1 and antioxidant enzymes. Life Sci 145:34-41. https:// doi.org/10.1016/j.lfs.2015.12.014

74. Kopff M, Zakrzewska I, Czernicki J, Klem J, Strzelczyk M, Chmielewski H (1996) Red blood cell superoxide dismutase and catalase activities in patients suffering from multiple sclerosis 
treated with adrenocorticotropic hormone. Pol J Pharmacol 48(4): 441-445

75. Schreibelt G, van Horssen J, van Rossum S, Dijkstra CD, Drukarch B, de Vries HE (2007) Therapeutic potential and biological role of endogenous antioxidant enzymes in multiple sclerosis pathology. Brain Res Rev 56(2):322-330. https://doi.org/10. 1016/j.brainresrev.2007.07.005

76. van Horssen J, Drexhage JA, Flor T, Gerritsen W, van der Valk P, de Vries HE (2010) Nrf2 and DJ1 are consistently upregulated in inflammatory multiple sclerosis lesions. Free Radic Biol Med 49(8):1283-1289. https://doi.org/10.1016/j.freeradbiomed.2010. 07.013

77. Schulze-Topphoff U, Varrin-Doyer M, Pekarek K, Spencer CM, Shetty A, Sagan SA, Cree BA, Sobel RA et al (2016) Dimethyl fumarate treatment induces adaptive and innate immune modulation independent of Nrf2. Proc Natl Acad Sci USA 113(17):47774782. https://doi.org/10.1073/pnas.1603907113

78. Albrecht P, Bouchachia I, Goebels N, Henke N, Hofstetter HH, Issberner A, Kovacs Z, Lewerenz J et al (2012) Effects of dimethyl fumarate on neuroprotection and immunomodulation. J Neuroinflammation 9(1):1-10. https://doi.org/10.1186/17422094-9-163

79. Gill AJ, Kolson DL (2013) Dimethyl fumarate modulation of immune and antioxidant responses: application to HIV therapy. Crit Rev Immunol 33(4):307-359

80. Huang H, Taraboletti A, Shriver LP (2015) Dimethyl fumarate modulates antioxidant and lipid metabolism in oligodendrocytes. Redox Biol 5:169-175. https://doi.org/10.1016/j.redox.2015.04. 011

81. Fox RJ, Miller DH, Phillips JT, Hutchinson M, Havrdova E, Kita M, Yang M, Raghupathi K et al (2012) Placebo-controlled phase 3 study of oral BG-12 or glatiramer in multiple sclerosis. N Engl J Med 367(12):1087-1097. https://doi.org/10.1056/ NEJMoa1206328

82. Gold PW, Pavlatou MG, Carlson PJ, Luckenbaugh DA, Costello R, Bonne O, Csako G, Drevets WC et al (2012) Unmedicated, remitted patients with major depression have decreased serum immunoglobulin A. Neurosci Lett 520(1):1-5. https://doi.org/10. 1016/j.neulet.2012.04.072

83. Kappos L, Giovannoni G, Gold R, Phillips JT, Arnold DL, Hotermans C, Zhang A, Viglietta V et al (2015) Time course of clinical and neuroradiological effects of delayed-release dimethyl fumarate in multiple sclerosis. Eur J Neurol 22(4):664-671. https://doi.org/10.1111/ene.12624

84. Gold R, Giovannoni G, Phillips JT, Fox RJ, Zhang A, Meltzer L, Kurukulasuriya NC (2015) Efficacy and safety of delayed-release dimethyl fumarate in patients newly diagnosed with relapsingremitting multiple sclerosis (RRMS). Mult Scler 21(1):57-66. https://doi.org/10.1177/1352458514537013

85. Matolcsi J, Rozsa C (2015) [Extending therapeutic possibilities in relapsing-remitting multiple sclerosis: dimethyl fumarate]. Ideggyogyaszati Sz 68(1-2):7-14

86. Mao P, Manczak M, Shirendeb UP, Reddy PH (2013) MitoQ, a mitochondria-targeted antioxidant, delays disease progression and alleviates pathogenesis in an experimental autoimmune encephalomyelitis mouse model of multiple sclerosis. Biochim Biophys Acta (BBA) - Mol Basis Dis 1832(12):2322-2331. https://doi.org/ 10.1016/j.bbadis.2013.09.005

87. Sanoobar M, Eghtesadi S, Azimi A, Khalili M, Khodadadi B, Jazayeri S, Gohari MR, Aryaeian N (2015) Coenzyme Q10 supplementation ameliorates inflammatory markers in patients with multiple sclerosis: a double blind, placebo, controlled randomized clinical trial. Nutr Neurosci 18(4):169-176. https://doi.org/10. 1179/1476830513y.0000000106

88. Sanoobar M, Eghtesadi S, Azimi A, Khalili M, Jazayeri S, Reza Gohari M (2013) Coenzyme Q10 supplementation reduces oxidative stress and increases antioxidant enzyme activity in patients with relapsing-remitting multiple sclerosis. Int $\mathrm{J}$ Neurosci 123(11):776-782. https://doi.org/10.3109/00207454.2013. 801844

89. Morris G, Walder K, Puri BK, Berk M, Maes M (2016) The deleterious effects of oxidative and nitrosative stress on palmitoylation, membrane lipid rafts and lipid-based cellular signalling: new drug targets in neuroimmune disorders. Mol Neurobiol 53(7):4638-4658. https://doi.org/10.1007/s12035015-9392-y

90. Richard D, Kefi K, Barbe U, Bausero P, Visioli F (2008) Polyunsaturated fatty acids as antioxidants. Pharmacol Res 57(6):451-455. https://doi.org/10.1016/j.phrs.2008.05.002

91. Maes M, Galecki P, Chang Y, Berk M (2011) A review on the oxidative and nitrosative stress (O\&NS) pathways in major depression and their possible contribution to the (neuro)degenerative processes in that illness. Prog NeuroPsychopharmacol Biol Psychiatry 35:676-692

92. Xu Y, Wang C, Klabnik JJ, O'Donnell JM (2014) Novel therapeutic targets in depression and anxiety: antioxidants as a candidate treatment. Curr Neuropharmacol 12(2):108-119. https://doi.org/ 10.2174/1570159X11666131120231448

93. Vargas HO, Nunes SO, Pizzo de Castro M, Bortolasci CC, Sabbatini Barbosa D, Kaminami Morimoto H, Venugopal K, Dodd S et al (2013) Oxidative stress and lowered total antioxidant status are associated with a history of suicide attempts. J Affect Disord 150(3):923-930. https://doi.org/10.1016/j.jad.2013.05. 016

94. Gawryluk J, Wang J, Andreazza A, Shao L, Young L (2011) Decreased levels of glutathione, the major brain antioxidant, in post-mortem prefrontal cortex from patients with psychiatric disorders. Int J Neuropsychopharmacol 14:123-130

95. Gawryluk JW, Wang JF, Andreazza AC, Shao L, Yatham LN, Young LT (2011) Prefrontal cortex glutathione S-transferase levels in patients with bipolar disorder, major depression and schizophrenia. Int J Neuropsychopharmacol 14(8):1069-1074. https://doi. org/10.1017/s1461145711000617

96. Maes M, Mihaylova I, Kubera M, Uytterhoeven M, Vrydags N, Bosmans E (2011) Lower whole blood glutathione peroxidase (GPX) activity in depression, but not in myalgic encephalomyelitis / chronic fatigue syndrome: another pathway that may be associated with coronary artery disease and neuroprogression in depression. Neuro Endocrinol Lett 32(2):133-140

97. Aydin EP, Genc A, Dalkiran M, Uyar ET, Deniz I, Ozer OA, Karamustafalioglu KO (2017) Thioredoxin is not a marker for treatment-resistance depression but associated with cognitive function: An rTMS study. Prog Neuropsychopharmacol Biol Psychiatry. https://doi.org/10.1016/j.pnpbp.2017.04.025

98. Tsai MC, Huang TL (2016) Increased activities of both superoxide dismutase and catalase were indicators of acute depressive episodes in patients with major depressive disorder. Psychiatry Res 235:38-42. https://doi.org/10.1016/j.psychres.2015.12.005

99. Russo AJ (2010) Increased serum $\mathrm{Cu} / \mathrm{Zn}$ SOD in individuals with clinical depression normalizes after zinc and anti-oxidant therapy. Nutr Metab Insights 3:37-42. https://doi.org/10.4137/NMI.S5044

100. Herken H, Gurel A, Selek S, Armutcu F, Ozen ME, Bulut M, Kap O, Yumru M et al (2007) Adenosine deaminase, nitric oxide, superoxide dismutase, and xanthine oxidase in patients with major depression: impact of antidepressant treatment. Arch Med Res 38(2):247-252. https://doi.org/10.1016/j.arcmed.2006.10.005

101. Martin-de-Saavedra MD, Budni J, Cunha MP, Gomez-Rangel V, Lorrio S, Del Barrio L, Lastres-Becker I, Parada E et al (2013) Nrf2 participates in depressive disorders through an antiinflammatory mechanism. Psychoneuroendocrinology 38(10): 2010-2022. https://doi.org/10.1016/j.psyneuen.2013.03.020 
102. Bouayed J, Bohn T (2010) Exogenous antioxidants-doubleedged swords in cellular redox state: health beneficial effects at physiologic doses versus deleterious effects at high doses. Oxidative Med Cell Longev 3(4):228-237. https://doi.org/10. 4161/oxim.3.4.12858

103. Forester BP, Harper DG, Georgakas J, Ravichandran C, Madurai N, Cohen BM (2015) Antidepressant effects of open label treatment with coenzyme Q10 in geriatric bipolar depression. J Clin Psychopharmacol 35(3):338-340. https://doi.org/10.1097/jcp. 0000000000000326

104. Forester BP, Zuo CS, Ravichandran C, Harper DG, Du F, Kim S, Cohen BM, Renshaw PF (2012) Coenzyme Q10 effects on creatine kinase activity and mood in geriatric bipolar depression. $\mathrm{J}$ Geriatr Psychiatry Neurol 25(1):43-50. https://doi.org/10.1177/ 0891988712436688

105. Gautam M, Agrawal M, Gautam M, Sharma P, Gautam AS, Gautam S (2012) Role of antioxidants in generalised anxiety disorder and depression. Indian J Psychiatry 54(3):244-247. https:// doi.org/10.4103/0019-5545.102424

106. Martins JG (2009) EPA but not DHA appears to be responsible for the efficacy of omega-3 long chain polyunsaturated fatty acid supplementation in depression: evidence from a meta-analysis of randomized controlled trials. J Am Coll Nutr 28(5):525-542

107. Fernandes BS, Dean OM, Dodd S, Malhi GS, Berk M (2016) NAcetylcysteine in depressive symptoms and functionality: a systematic review and meta-analysis. J Clin Psychiatry 77(4):e457e466. https://doi.org/10.4088/JCP.15r09984

108. Lopresti A, Maes M, Maker G, Hood S, Drummond P (2014) Curcumin for the treatment of major depression: a randomised, double-blind, placebo controlled study. J Affect Disord 167:368375

109. Pathak L, Agrawal Y, Dhir A (2013) Natural polyphenols in the management of major depression. Expert Opin Investig Drugs 22(7):863-880. https://doi.org/10.1517/13543784.2013.794783

110. Navikas V, Link H (1996) Cytokines and the pathogenesis of multiple sclerosis. J Neurosci Res 45:322-333

111. Tejera-Alhambra M, Casrouge A, de Andrés C, Seyfferth A, Ramos-Medina R, Alonso B, Vega J, Fernández-Paredes L et al (2015) Plasma biomarkers discriminate clinical forms of multiple sclerosis. PloS One 10(6):e0128952. https://doi.org/10.1371/ journal.pone.0128952

112. Martins T, Rose J, Jaskowski T, Wilson A, Husebye D, Seraj H (2011) Analysis of proinflammatory and anti-inflammatory cytokine serum concentrations in patients with multiple sclerosis by using a multiplexed immunoassay. Am J Clin Pathol 136:696-704

113. Matsushita T, Tateishi T, Isobe N, Yonekawa T, Yamasaki R, Matsuse D, Murai H, Kira J (2013) Characteristic cerebrospinal fluid cytokine/chemokine profiles in neuromyelitis optica, relapsing remitting or primary progressive multiple sclerosis. PloS one 8(4):e61835. https://doi.org/10.1371/journal.pone.0061835

114. Beck J, Rondot P, Catinot L, Falcoff E, Kirchner H, Wietzerbin J (1988) Increased production of interferon gamma and tumor necrosis factor precedes clinical manifestation in multiple sclerosis: do cytokines trigger off exacerbations. Acta Neurol Scand 78: 318-323

115. Maimone D, Gregory S, Arnason B, Reder A (1991) Cytokine levels in the cerebrospinal fluid and serum of patients with multiple sclerosis. J Neuroimmunol 32:67-74

116. Flachenecker P, Bihler I, Weber F, Gottschalk M, Toyka K, Rieckmann P (2004) Cytokine mRNA expression in patients with multiple sclerosis and fatigue. Mult Scler 10:165-169

117. Kallaur AP, Reiche EM, Oliveira SR, Simao AN, Pereira WL, Alfieri DF, Flauzino T, Proenca CM et al (2017) Genetic, immune-inflammatory, and oxidative stress biomarkers as predictors for disability and disease progression in multiple sclerosis. Mol
Neurobiol. 54(1):31-44. https://doi.org/10.1007/s12035-0159648-6

118. Kallaur AP, Oliveira SR, Simao AN, de Almeida ER, Morimoto HK, Alfieri DF, Pereira WL, Borelli SD et al (2014) Tumor necrosis factor beta NcoI polymorphism is associated with inflammatory and metabolic markers in multiple sclerosis patients. J Neurol Sci 346(1-2):156-163. https://doi.org/10.1016/j.jns.2014.08.016

119. Sorenson M, Janusek L, Mathews H (2013) Psychological stress and cytokine production in multiple sclerosis: correlation with disease symptomatology. Biol Res Nurs 15(2):226-233. https:// doi.org/10.1177/1099800411425703

120. Rossi S, Motta C, Studer V, Macchiarulo G, Volpe E, Barbieri F, Ruocco G, Buttari F et al (2014) Interleukin-1beta causes excitotoxic neurodegeneration and multiple sclerosis disease progression by activating the apoptotic protein p53. Mol Neurodegener 9:56. https://doi.org/10.1186/1750-1326-9-56

121. Seppi D, Puthenparampil M, Federle L, Ruggero S, Toffanin E, Rinaldi F, Perini P, Gallo P (2014) Cerebrospinal fluid IL-1beta correlates with cortical pathology load in multiple sclerosis at clinical onset. J Neuroimmunol 270(1-2):56-60. https://doi.org/10. 1016/j.jneuroim.2014.02.014

122. Balasa R, Bajko Z, Hutanu A (2013) Serum levels of IL-17A in patients with relapsing-remitting multiple sclerosis treated with interferon-beta. Mult Scler 19(7):885-890. https://doi.org/10. 1177/1352458512468497

123. Babaloo Z, Aliparasti MR, Babaiea F, Almasi S, Baradaran B, Farhoudi M (2015) The role of Th17 cells in patients with relapsing-remitting multiple sclerosis: interleukin-17A and interleukin-17F serum levels. Immunol Lett 164(2):76-80. https://doi.org/10.1016/j.imlet.2015.01.001

124. Romme Christensen J, Bornsen L, Hesse D, Krakauer M, Sorensen P, Sondergaard H (2012) Cellular sources of dysregulated cytokines in relapsing-remitting multiple sclerosis. J Neuroinflammation 9:215

125. Vaknin-Dembinsky A, Balashov K, Weiner HL (2006) IL-23 is increased in dendritic cells in multiple sclerosis and downregulation of IL-23 by antisense oligos increases dendritic cell IL-10 production. J Immunol (Baltimore, Md : 1950) 176(12): 7768-7774

126. Malhotra S, Rio J, Urcelay E, Nurtdinov R, Bustamante MF, Fernandez O, Oliver B, Zettl U et al (2015) NLRP3 inflammasome is associated with the response to IFN-beta in patients with multiple sclerosis. Brain 138(Pt 3):644-652. https:// doi.org/10.1093/brain/awu388

127. Oreja-Guevara C, Ramos-Cejudo J, Aroeira LS, Chamorro B, Diez-Tejedor E (2012) TH1/TH2 Cytokine profile in relapsingremitting multiple sclerosis patients treated with Glatiramer acetate or Natalizumab. BMC Neurol 12(1):1-6. https://doi.org/10. 1186/1471-2377-12-95

128. Berk M, Williams LJ, Jacka FN, O'Neil A, Pasco JA, Moylan S, Allen NB, Stuart AL et al (2013) So depression is an inflammatory disease, but where does the inflammation come from? BMC Med 11:200. https://doi.org/10.1186/1741-7015-11-200

129. Maes M, Lambrechts J, Bosmans E, Jacobs J, Suy E, Vandervorst C, de Jonckheere C, Minner B et al (1992) Evidence for a systemic immune activation during depression: results of leukocyte enumeration by flow cytometry in conjunction with monoclonal antibody staining. Psychol Med 22(1):45-53

130. Maes M (1995) Evidence for an immune response in major depression: a review and hypothesis. Prog Neuropsychopharmacol Biol Psychiatry 19(1):11-38

131. Maes M, Galecki P, Chang YS, Berk M (2011) A review on the oxidative and nitrosative stress (O\&NS) pathways in major depression and their possible contribution to the (neuro)degenerative processes in that illness. Prog 
Neuropsychopharmacol Biol Psychiatry 35(3):676-692. https:// doi.org/10.1016/j.pnpbp.2010.05.004

132. Maes M, Kubera M, Obuchowiczwa E, Goehler L, Brzeszcz J (2011) Depression's multiple comorbidities explained by (neuro)inflammatory and oxidative \& nitrosative stress pathways. Neuro Endocrinol Lett 32:7-24

133. Mossner R, Mikova O, Koutsilieri E, Saoud M, Ehlis AC, Muller N, Fallgatter AJ, Riederer P (2007) Consensus paper of the WFSBP Task Force on Biological Markers: biological markers in depression. World J Biol Psychiatry : Off J World Fed Soc Biol Psychiatry 8(3):141-174. https://doi.org/10.1080/ 15622970701263303

134. Dowlati Y, Herrmann N, Swardfager W, Liu H, Sham L, Reim E (2010) A meta-analysis of cytokines in major depression. Biol Psychiatry 67:446-457

135. Young JJ, Bruno D, Pomara N (2014) A review of the relationship between proinflammatory cytokines and major depressive disorder. J Affect Disord 169:15-20. https://doi.org/10.1016/j.jad. 2014.07.032

136. Iwata M, Ota KT, Duman RS (2013) The inflammasome: pathways linking psychological stress, depression, and systemic illnesses. Brain Behav Immun 31:105-114. https://doi.org/10. 1016/j.bbi.2012.12.008

137. Maes M (2008) The cytokine hypothesis of depression: inflammation, oxidative \& nitrosative stress (IO\&NS) and leaky gut as new targets for adjunctive treatments in depression. Neuro Endocrinol Lett 29(3):287-291

138. Lucas K, Morris G, Anderson G, Maes M (2015) The toll-like receptor radical cycle pathway: a new drug target in immunerelated chronic fatigue. CNS Neurol Disord Drug Targets 14(7): 838-854. https://doi.org/10.2174/1871527314666150317224645

139. Song C, Halbreich U, Han C, Leonard B, Luo H (2009) Imbalance between pro- and anti-inflammatory cytokines, and between Th1 and Th2 cytokines in depressed patients: the effect of electroacupuncture or fluoxetine treatment. Pharmacopsychiatry 42:182-188

140. Lewkowicz P, Lewkowicz N, Sasiak A, Tchorzewski H (2006) Lipopolysaccharide-activated CD4+CD25+ T regulatory cells inhibit neutrophil function and promote their apoptosis and death. J Immunol (Baltimore, Md : 1950) 177(10):7155-7163

141. Morris G, Maes M (2013) Myalgic encephalomyelitis/chronic fatigue syndrome and encephalomyelitis disseminata/multiple sclerosis show remarkable levels of similarity in phenomenology and neuroimmune characteristics. BMC Med 11(1):205

142. Morris G, Maes M (2012) A neuro-immune model of myalgic encephalomyelitis/chronic fatigue syndrome. Metab Brain Dis

143. van Horssen J, Singh S, van der Pol S, Kipp M, Lim JL, Peferoen L, Gerritsen W, Kooi EJ et al (2012) Clusters of activated microglia in normal-appearing white matter show signs of innate immune activation. J Neuroinflammation 9:156. https://doi.org/10.1186/ 1742-2094-9-156

144. van Noort JM, van den Elsen PJ, van Horssen J, Geurts JJ, van der Valk P, Amor S (2011) Preactive multiple sclerosis lesions offer novel clues for neuroprotective therapeutic strategies. CNS Neurol Disord Drug Targets 10(1):68-81

145. Politis M, Giannetti P, Su P, Turkheimer F, Keihaninejad S, Wu K, Waldman A, Malik O et al (2012) Increased PK11195 PET binding in the cortex of patients with MS correlates with disability. Neurology 79(6):523-530. https://doi.org/10.1212/WNL. 0b013e3182635645

146. Giannetti P, Politis M, Su P, Turkheimer F, Malik O, Keihaninejad S, Wu K, Reynolds R et al (2014) Microglia activation in multiple sclerosis black holes predicts outcome in progressive patients: an in vivo [(11)C](R)-PK11195-PET pilot study. Neurobiol Dis 65: 203-210. https://doi.org/10.1016/j.nbd.2014.01.018
147. Bogie JFJ, Stinissen P, Hendriks JJA (2014) Macrophage subsets and microglia in multiple sclerosis. Acta Neuropathol 128(2):191213. https://doi.org/10.1007/s00401-014-1310-2

148. Albert U, De Cori D, Aguglia A, Barbaro F, Bogetto F, Maina G (2015) Increased uric acid levels in bipolar disorder subjects during different phases of illness. J Affect Disord 173:170-175. https://doi.org/10.1016/j.jad.2014.11.005

149. Morris G, Maes M (2014) Oxidative and nitrosative stress and immune-inflammatory pathways in patients with myalgic encephalomyelitis (ME)/chronic fatigue syndrome (CFS). Curr Neuropharmacol 12:168-185

150. Freilich RW, Woodbury ME, Ikezu T (2013) Integrated expression profiles of mRNA and miRNA in polarized primary murine microglia. PloS one 8(11):e79416. https://doi.org/10.1371/journal. pone.0079416

151. Moore C, Rao V, Fuh S-C, Bedell B, Ludwin S, Bar-Or A, Antel J (2014) Implicating MicroRNAs as regulators of microglia and astrocyte responses in human CNS inflammatory disease (P5.018). Neurology 82 (10 Supplement)

152. Pogue AI, Li YY, Cui JG, Zhao Y, Kruck TP, Percy ME, Tarr MA, Lukiw WJ (2009) Characterization of an NF-kappaB-regulated, miRNA-146a-mediated down-regulation of complement factor $\mathrm{H}$ $(\mathrm{CFH})$ in metal-sulfate-stressed human brain cells. J Inorg Biochem 103(11):1591-1595. https://doi.org/10.1016/j.jinorgbio. 2009.05.012

153. Wang Y, Cella M, Mallinson K, Ulrich JD, Young KL, Robinette ML, Gilfillan S, Krishnan GM et al (2015) TREM2 lipid sensing sustains the microglial response in an Alzheimer's disease model. Cell 160(6):1061-1071. https://doi.org/10.1016/j.cell.2015.01. 049

154. Gonzalez R (2014) The relationship between bipolar disorder and biological rhythms. J Clin Psychiatry 75(04):e323-e331. https:// doi.org/10.4088/jcp.13r08507

155. Gonzalez H, Pacheco R (2014) T-cell-mediated regulation of neuroinflammation involved in neurodegenerative diseases. $\mathrm{J}$ Neuroinflammation 11:201. https://doi.org/10.1186/s12974-0140201-8

156. Gonzalez H, Elgueta D, Montoya A, Pacheco R (2014) Neuroimmune regulation of microglial activity involved in neuroinflammation and neurodegenerative diseases. J Neuroimmunol 274(1-2):1-13. https://doi.org/10.1016/j.jneuroim.2014.07.012

157. Brites D, Fernandes A (2015) Neuroinflammation and depression: microglia activation, extracellular microvesicles and microRNA dysregulation. Front Cell Neurosci 9:476. https://doi.org/10. 3389/fncel.2015.00476

158. Serafini G, Pompili M, Borgwardt S, Giuffra E, Howes O, Girardi $\mathrm{P}$, Amore M (2015) The role of white matter abnormalities in treatment-resistant depression: a systematic review. Curr Pharm Des 21(10):1337-1346

159. Santos LE, Beckman D, Ferreira ST (2015) Microglial dysfunction connects depression and Alzheimer's disease. Brain Behav Immun. https://doi.org/10.1016/j.bbi.2015.11.011

160. Yirmiya R, Rimmerman N, Reshef R Depression as a microglial disease. Trends Neurosci 38(10):637-658. https://doi.org/10. 1016/j.tins.2015.08.001

161. Steiner J, Walter M, Gos T, Guillemin G, Bernstein H, Sarnyai Z (2011) Severe depression is associated with increased microglial quinolinic acid in subregions of the anterior cingulate gyrus: evidence for an immune-modulated glutamatergic neurotransmission. J Neuroinflammation 8:1-9

162. Kreisel T, Frank M, Licht T, Reshef R, Ben-Menachem-Zidon O, Baratta M (2014) Dynamic microglial alterations underlie stressinduced depressive-like behavior and suppressed neurogenesis. Mol Psychiatry 19:699-709

163. Husain MI, Chaudhry IB, Husain N, Khoso AB, Rahman RR, Hamirani MM, Hodsoll J, Qurashi I, Deakin JF, Young AH 
(2017) Minocycline as an adjunct for treatment-resistant depressive symptoms: a pilot randomised placebo-controlled trial. J Psychopharmacol (Oxford, England):269881117724352. https:// doi.org/10.1177/0269881117724352

164. Dean OM, Kanchanatawan B, Ashton M, Mohebbi M, Ng CH, Maes M, Berk L, Sughondhabirom A, Tangwongchai S, Singh AB, McKenzie H, Smith DJ, Malhi GS, Dowling N, Berk M (2017) Adjunctive minocycline treatment for major depressive disorder: a proof of concept trial. Aust N Z J Psychiatry: 4867417709357. https://doi.org/10.1177/0004867417709357

165. Li Y, Xiao B, Qiu W, Yang L, Hu B, Tian X, Yang H (2010) Altered expression of CD4(+)CD25(+) regulatory T cells and its 5-HT(1a) receptor in patients with major depression disorder. J Affect Disord 124(1-2):68-75. https://doi.org/10.1016/j.jad. 2009.10.018

166. Centonze D, Muzio L, Rossi S, Furlan R, Bernardi G, Martino G (2010) The link between inflammation, synaptic transmission and neurodegeneration in multiple sclerosis. Cell Death Differ 17: 1083-1091

167. Campbell G, Ziabreva I, Reeve A, Krishnan K, Reynolds R, Howell O, Lassmann H, Turnbull D et al (2011) Mitochondrial DNA deletions and neurodegeneration in multiple sclerosis. Ann Neurol 69:481-492

168. Fischer M, Sharma R, Lim J, Haider L, Frischer J, Drexhage J (2012) NADPH oxidase expression in active multiple sclerosis lesions in relation to oxidative tissue damage and mitochondrial injury. Brain 135:886-899

169. Kidd P (2005) Neurodegeneration from mitochondrial insufficiency: nutrients, stem cells, growth factors, and prospects for brain rebuilding using integrative management. Altern Med Rev 10: 268-293

170. Witte M, Nijland P, Drexhage J, Gerritsen W, Geerts D, van Het Hof B (2013) Reduced expression of PGC-1alpha partly underlies mitochondrial changes and correlates with neuronal loss in multiple sclerosis cortex. Acta Neuropathol 125:231-243

171. Lu F, Selak M, O'Connor J, Croul S, Lorenzana C, Butunoi C (2000) Oxidative damage to mitochondrial DNA and activity of mitochondrial enzymes in chronic active lesions of multiple sclerosis. J Neurol Sci 177:95-103

172. Dutta R, McDonough J, Yin X, Peterson J, Chang A, Torres T (2006) Mitochondrial dysfunction as a cause of axonal degeneration in multiple sclerosis patients. Ann Neurol 59:478-489

173. Mahad D, Lassmann H, Turnbull D (2008) Review: mitochondria and disease progression in multiple sclerosis. Neuropathol Appl Neurobiol 34:577-589

174. Mahad D, Ziabreva I, Campbell G, Lax N, White K, Hanson P (2009) Mitochondrial changes within axons in multiple sclerosis. Brain 132:1161-1174

175. Reinke S, Broadhurst D, Sykes B, Baker G, Catz I, Warren K (2014) Metabolomic profiling in multiple sclerosis: insights into biomarkers and pathogenesis. Mult Scler 20:1396-1400

176. Lutz N, Viola A, Malikova I, Confort-Gouny S, Ranjeva J, Pelletier J (2006) High-resolution 1 H NMR spectroscopy reveals differences in CSF metabolic profiles for MS patients with inflammatory vs. non-inflammatory plaques. Proc Intl Soc Mag Reson Med 14:1986

177. Lazzarino G, Amorini A, Eikelenboom M, Killestein J, Belli A, Di Pietro V (2010) Cerebrospinal fluid ATP metabolites in multiple sclerosis. Mult Scler 16:549-554

178. Kauv P, Ayache SS, Créange A, Chalah MA, Lefaucheur J-P, Hodel J, Brugières P (2017) Adenosine triphosphate metabolism measured by phosphorus magnetic resonance spectroscopy: a potential biomarker for multiple sclerosis severity. Eur Neurol 77(56):316-321. https://doi.org/10.1159/000475496
179. Cox IJ, Puri BK (2004) In vivo MR spectroscopy in diagnosis and research of neuropsychiatric disorders. Prostaglandins Leukot Essent Fatty Acids 70. https://doi.org/10.1016/j.plefa.2003.12.010

180. Wood ET, Ronen I, Techawiboonwong A, Jones CK, Barker PB, Calabresi P, Harrison D, Reich DS (2012) Investigating axonal damage in multiple sclerosis by diffusion tensor spectroscopy. $\mathrm{J}$ Neurosci 32(19):6665-6669. https://doi.org/10.1523/jneurosci. 0044-12.2012

181. Wood ET, Ercan E, Sati P, Cortese ICM, Ronen I, Reich DS (2017) Longitudinal MR spectroscopy of neurodegeneration in multiple sclerosis with diffusion of the intra-axonal constituent $\mathrm{N}$-acetylaspartate. NeuroImage: Clinical 15:780-788. https:// doi.org/10.1016/j.nicl.2017.06.028

182. Gardner A, Boles R (2011) Beyond the serotonin hypothesis: mitochondria, inflammation and neurodegeneration in major depression and affective spectrum disorders. Prog Neuropsychopharmacol Biol Psychiatry 35:730-743

183. Sarandol A, Sarandol E, Eker S, Erdinc S, Vatansever E, Kirli S (2007) Major depressive disorder is accompanied with oxidative stress: short-term antidepressant treatment does not alter oxidative-antioxidative systems. Hum Psychopharmacol 22:6773

184. Klinedinst NJ, Regenold WT (2015) A mitochondrial bioenergetic basis of depression. J Bioenerg Biomembr 47(1-2):155-171. https://doi.org/10.1007/s10863-014-9584-6

185. Videbech P (2000) PET measurements of brain glucose metabolism and blood flow in major depressive disorder: a critical review. Acta Psychiatr Scand 101:11-20

186. Iosifescu DV, Bolo NR, Nierenberg AA, Jensen JE, Fava M, Renshaw PF Brain bioenergetics and response to triiodothyronine augmentation in major depressive disorder. Biol Psychiatry 63(12):1127-1134. https://doi.org/10.1016/j.biopsych.2007.11. 020

187. Mayberg H, Liotti M, Brannan S, McGinnis S, Mahurin R, Jerabek P (1999) Reciprocal limbic-cortical function and negative mood: converging PET findings in depression and normal sadness. Am J Psychiatry 156:675-682

188. Moretti A, Gorini A, Villa R (2003) Affective disorders, antidepressant drugs and brain metabolism. Mol Psychiatry 8:773-785

189. Hroudova J, Fisar Z, Kitzlerova E, Zverova M, Raboch J (2013) Mitochondrial respiration in blood platelets of depressive patients. Mitochondrion 6:795-800

190. Berk M, Williams L, Jacka F, O'Neil A, Pasco J, Moylan S (2013) So depression is an inflammatory disease, but where does the inflammation come from? BMC Med 11:200

191. Gardner A, Johansson A, Wibom R, Nennesmo I, von Dobeln U, Hagenfeldt L (2003) Alterations of mitochondrial function and correlations with personality traits in selected major depressive disorder patients. J Affect Disord 76:55-68

192. Karabatsiakis A, Bock C, Salinas-Manrique J, Kolassa S, Calzia E, Dietrich DE, Kolassa IT (2014) Mitochondrial respiration in peripheral blood mononuclear cells correlates with depressive subsymptoms and severity of major depression. Trans1 Psychiatry 4:e397. https://doi.org/10.1038/tp.2014.44

193. Bodet D, Glaize G, Dabadie MP, Geffard M (2004) Suivi immunobiologique de malades atteints de sclérose en plaques. Immuno-Analyse Biologie Spécialisée 19(3):138-147. https:// doi.org/10.1016/j.immbio.2004.03.007

194. Geffard M, Bodet D, Martinet Y, Dabadie M (2002) Detection of the specific IgM and IgA circulating in sera of multiple sclerosis patients: interest and perspectives. Immunoanalyse Biologie Specialisee 17:302-310

195. Miyake S, Kim S, Suda W, Oshima K, Nakamura M, Matsuoka T, Chihara N, Tomita A et al (2015) Dysbiosis in the gut microbiota of patients with multiple sclerosis, with a striking depletion of 
species belonging to Clostridia XIVa and IV clusters. PloS One 10(9):e0137429. https://doi.org/10.1371/journal.pone.0137429

196. Ivanov II, de Llanos FR, Manel N, Yoshinaga K, Rifkin DB, Sartor RB, Finlay BB, Littman DR (2008) Specific microbiota direct the differentiation of Th17 cells in the mucosa of the small intestine. Cell Host Microbe 4(4):337-349. https://doi.org/10. 1016/j.chom.2008.09.009

197. Kamada N, Núñez G (2013) Role of the gut microbiota in the development and function of lymphoid cells. J Immunol (Baltimore, Md : 1950) 190(4):1389-1395. https://doi.org/10. 4049/jimmunol.1203100

198. Karczewski J, Poniedzialek B, Adamski Z, Rzymski P (2014) The effects of the microbiota on the host immune system. Autoimmunity 47(8):494-504. https://doi.org/10.3109/ 08916934.2014.938322

199. Ochoa-Reparaz J, Kasper LH (2014) Gut microbiome and the risk factors in central nervous system autoimmunity. FEBS Lett 588(22):4214-4222. https://doi.org/10.1016/j.febslet.2014.09. 024

200. Joscelyn J, Kasper LH (2014) Digesting the emerging role for the gut microbiome in central nervous system demyelination. Mult Scler 20(12):1553-1559. https://doi.org/10.1177/ 1352458514541579

201. Shan L, Siliciano RF (2014) Unraveling the relationship between microbial translocation and systemic immune activation in HIV infection. J Clin Investig 124(6):2368-2371. https://doi.org/10. 1172/jci75799

202. Berer K, Krishnamoorthy G (2014) Microbial view of central nervous system autoimmunity. FEBS Lett 588(22):4207-4213. https://doi.org/10.1016/j.febslet.2014.04.007

203. Ruff WE, Kriegel MA (2015) Autoimmune host-microbiota interactions at barrier sites and beyond. Trends Mol Med 21(4):233244. https://doi.org/10.1016/j.molmed.2015.02.006

204. Yacyshyn B, Meddings J, Sadowski D, Bowen-Yacyshyn MB (1996) Multiple sclerosis patients have peripheral blood CD45RO+ B cells and increased intestinal permeability. Dig Dis Sci 41(12):2493-2498

205. Fasano A, Shea-Donohue T (2005) Mechanisms of disease: the role of intestinal barrier function in the pathogenesis of gastrointestinal autoimmune diseases. Nat Clin Pract Gastroenterolog Hepatol 2(9):416-422. https://doi.org/10.1038/ncpgasthep0259

206. Nouri M, Bredberg A, Westrom B, Lavasani S (2014) Intestinal barrier dysfunction develops at the onset of experimental autoimmune encephalomyelitis, and can be induced by adoptive transfer of auto-reactive T cells. PloS One 9(9):e106335. https://doi.org/ 10.1371/journal.pone.0106335

207. Maes M, Kubera M, Leunis JC (2008) The gut-brain barrier in major depression: intestinal mucosal dysfunction with an increased translocation of LPS from gram negative enterobacteria (leaky gut) plays a role in the inflammatory pathophysiology of depression. Neuro Endocrinol Lett 29(1):117-124

208. Maes M, Kubera M, Leunis JC, Berk M, Geffard M, Bosmans E (2013) In depression, bacterial translocation may drive inflammatory responses, oxidative and nitrosative stress (O\&NS), and autoimmune responses directed against O\&NS-damaged neoepitopes. Acta Psychiatr Scand 127(5):344-354. https://doi. org/10.1111/j.1600-0447.2012.01908.x

209. Wang Y, Kasper LH (2014) The role of microbiome in central nervous system disorders. Brain Behav Immun 38:1-12. https:// doi.org/10.1016/j.bbi.2013.12.015

210. Rogers GB, Keating DJ, Young RL, Wong ML, Licinio J, Wesselingh $S$ (2016) From gut dysbiosis to altered brain function and mental illness: mechanisms and pathways. Mol Psychiatry. https://doi.org/10.1038/mp.2016.50

211. Jiang H, Ling Z, Zhang Y, Mao H, Ma Z, Yin Y, Wang W, Tang W et al (2015) Altered fecal microbiota composition in patients with major depressive disorder. Brain Behav Immun 48:186-194. https://doi.org/10.1016/j.bbi.2015.03.016

212. Foster JA, McVey Neufeld KA (2013) Gut-brain axis: how the microbiome influences anxiety and depression. Trends Neurosci 36(5):305-312. https://doi.org/10.1016/j.tins.2013.01.005

213. Burokas A, Moloney RD, Dinan TG, Cryan JF (2015) Microbiota regulation of the Mammalian gut-brain axis. Adv Appl Microbiol 91:1-62. https://doi.org/10.1016/bs.aambs.2015.02.001

214. Borre YE, Moloney RD, Clarke G, Dinan TG, Cryan JF (2014) The impact of microbiota on brain and behavior: mechanisms \& therapeutic potential. Adv Exp Med Biol 817:373-403. https:// doi.org/10.1007/978-1-4939-0897-4_17

215. Hill M, Tanguy-Royer S, Royer P, Chauveau C, Asghar K, Tesson L, Lavainne F, Remy S et al (2007) IDO expands human CD4+ $\mathrm{CD} 25$ high regulatory $\mathrm{T}$ cells by promoting maturation of LPStreated dendritic cells. Eur J Immunol 37(11):3054-3062. https:// doi.org/10.1002/eji.200636704

216. Poujol F, Monneret G, Pachot A, Textoris J, Venet F (2015) Altered T Lymphocyte proliferation upon lipopolysaccharide challenge ex vivo. PloS One 10(12):e0144375. https://doi.org/ 10.1371/journal.pone. 0144375

217. Campbell AW (2014) Autoimmunity and the Gut. Autoimmune Dis 2014(2014):1-12. https://doi.org/10.1155/2014/152428

218. Gárate I, García-Bueno B, Madrigal JLM, Bravo L, Berrocoso E, Caso JR, Micó JA, Leza JC (2011) Origin and consequences of brain toll-like receptor 4 pathway stimulation in an experimental model of depression. J Neuroinflammation 8(1):151. https://doi. org/10.1186/1742-2094-8-151

219. Gobbi C, Rocca MA, Riccitelli G, Pagani E, Messina R, Preziosa P, Colombo B, Rodegher M et al (2014) Influence of the topography of brain damage on depression and fatigue in patients with multiple sclerosis. Mult Scler 20(2):192-201. https://doi.org/10. 1177/1352458513493684

220. Patejdl R, Penner IK, Noack TK, Zettl UK (2016) Multiple sclerosis and fatigue: a review on the contribution of inflammation and immune-mediated neurodegeneration. Autoimmun Rev 15(3): 210-220. https://doi.org/10.1016/j.autrev.2015.11.005

221. Pujol J, Bello J, Deus J, Marti-Vilalta JL, Capdevila A (1997) Lesions in the left arcuate fasciculus region and depressive symptoms in multiple sclerosis. Neurology 49(4):1105-1110

222. Pujol J, Bello J, Deus J, Cardoner N, Marti-Vilalta JL, Capdevila A (2000) Beck depression inventory factors related to demyelinating lesions of the left arcuate fasciculus region. Psychiatry Res 99(3):151-159

223. Bakshi R, Czarnecki D, Shaikh ZA, Priore RL, Janardhan V, Kaliszky Z, Kinkel PR (2000) Brain MRI lesions and atrophy are related to depression in multiple sclerosis. Neuroreport 11(6): $1153-1158$

224. Zorzon M, de Masi R, Nasuelli D, Ukmar M, Mucelli RP, Cazzato G, Bratina A, Zivadinov R (2001) Depression and anxiety in multiple sclerosis. A clinical and MRI study in 95 subjects. J Neurol 248(5):416-421

225. Zorzon M, Zivadinov R, Nasuelli D, Ukmar M, Bratina A, Tommasi MA, Mucelli RP, Brnabic-Razmilic O et al (2002) Depressive symptoms and MRI changes in multiple sclerosis. Eur J Neurol 9(5):491-496

226. Feinstein A, Roy P, Lobaugh N, Feinstein K, O'Connor P, Black S (2004) Structural brain abnormalities in multiple sclerosis patients with major depression. Neurology 62(4):586-590

227. Gold SM, Kern KC, O'Connor MF, Montag MJ, Kim A, Yoo YS, Giesser BS, Sicotte NL (2010) Smaller cornu ammonis 2-3/dentate gyrus volumes and elevated cortisol in multiple sclerosis patients with depressive symptoms. Biol Psychiatry 68(6):553-559. https://doi.org/10.1016/j.biopsych.2010.04.025

228. Kiy G, Lehmann P, Hahn HK, Eling P, Kastrup A, Hildebrandt H (2011) Decreased hippocampal volume, indirectly measured, is 
associated with depressive symptoms and consolidation deficits in multiple sclerosis. Mult Scler 17(9):1088-1097. https://doi.org/ $10.1177 / 1352458511403530$

229. Gold SM, O'Connor MF, Gill R, Kern KC, Shi Y, Henry RG, Pelletier D, Mohr DC et al (2014) Detection of altered hippocampal morphology in multiple sclerosis-associated depression using automated surface mesh modeling. Hum Brain Mapp 35(1):30 37. https://doi.org/10.1002/hbm.22154

230. Kern JK, Geier DA, Sykes LK, Haley BE, Geier MR (2016) The relationship between mercury and autism: a comprehensive review and discussion. J Trace Elem Med Biol 37:8-24. https:// doi.org/10.1016/j.jtemb.2016.06.002

231. Mancini A, Gaetani L, Di Gregorio M, Tozzi A, Ghiglieri V, Calabresi P, Di Filippo M (2017) Hippocampal neuroplasticity and inflammation: relevance for multiple sclerosis. Mult Scler Demyelinating Disord 2(1):2. https://doi.org/10.1186/s40893017-0019-1

232. Campbell S, Marriott M, Nahmias C, MacQueen GM (2004) Lower hippocampal volume in patients suffering from depression: a meta-analysis. Am J Psychiatry 161(4):598-607. https://doi.org/ 10.1176/appi.ajp.161.4.598

233. Zou K, Deng W, Li T, Zhang B, Jiang L, Huang C, Sun X, Sun X (2010) Changes of brain morphometry in first-episode, drug-naive, non-late-life adult patients with major depression: an optimized voxel-based morphometry study. Biol Psychiatry 67(2): 186-188. https://doi.org/10.1016/j.biopsych.2009.09.014

234. Cole J, Costafreda SG, McGuffin P, Fu CH (2011) Hippocampal atrophy in first episode depression: a meta-analysis of magnetic resonance imaging studies. J Affect Disord 134(1-3):483-487. https://doi.org/10.1016/j.jad.2011.05.057

235. Colasanti A, Guo Q, Giannetti P, Wall MB, Newbould RD, Bishop C, Onega M, Nicholas R et al Hippocampal neuroinflammation, functional connectivity, and depressive symptoms in multiple sclerosis. Biol Psychiatry. https://doi.org/10.1016/j.biopsych.2015.11. 022

236. Michoux N, Guillet A, Rommel D, Mazzamuto G, Sindic C, Duprez T (2015) Texture analysis of T2-weighted MR images to assess acute inflammation in brain MS lesions. PLoS One 10(12): e0145497. https://doi.org/10.1371/journal.pone.0145497

237. Stadelmann C, Wegner C, Brück W (2011) Inflammation, demyelination, and degeneration - recent insights from MS pathology. Biochim Biophys Acta (BBA) - Mol Basis Dis 1812(2):275-282. https://doi.org/10.1016/j.bbadis.2010.07.007

238. Paolillo A, Piattella MC, Pantano P, Di Legge S, Caramia F, Russo P, Lenzi GL, Pozzilli C (2004) The relationship between inflammation and atrophy in clinically isolated syndromes suggestive of multiple sclerosis: a monthly MRI study after triple-dose gadolinium-DTPA. J Neurol 251(4):432-439. https://doi.org/10.1007/ s00415-004-0349-8

239. Lassmann H (2012) Cortical lesions in multiple sclerosis: inflammation versus neurodegeneration. Brain 135(Pt 10):2904-2905. https://doi.org/10.1093/brain/aws260

240. Vercellino M, Masera S, Lorenzatti M, Condello C, Merola A, Mattioda A, Tribolo A, Capello E et al (2009) Demyelination, inflammation, and neurodegeneration in multiple sclerosis deep gray matter. J Neuropathol Exp Neurol 68(5):489-502. https:// doi.org/10.1097/NEN.0b013e3181a19a5a

241. Di Filippo M, Sarchielli P, Picconi B, Calabresi P (2008) Neuroinflammation and synaptic plasticity: theoretical basis for a novel, immune-centred, therapeutic approach to neurological disorders. Trends Pharmacol Sci 29(8):402-412. https://doi.org/ 10.1016/j.tips.2008.06.005

242. Mandolesi G, Gentile A, Musella A, Fresegna D, De Vito F, Bullitta S, Sepman H, Marfia GA et al (2015) Synaptopathy connects inflammation and neurodegeneration in multiple sclerosis.
Nat Rev Neurol 11(12):711-724. https://doi.org/10.1038/ nrneurol.2015.222

243. Geurts JJ, Bo L, Roosendaal SD, Hazes T, Daniels R, Barkhof F, Witter MP, Huitinga I et al (2007) Extensive hippocampal demyelination in multiple sclerosis. J Neuropathol Exp Neurol 66(9): 819-827. https://doi.org/10.1097/nen.0b013e3181461f54

244. Papadopoulos AS, Cleare AJ (2011) Hypothalamic-pituitary-adrenal axis dysfunction in chronic fatigue syndrome. Nat Rev Endocrinol 8(1):22-32. https://doi.org/10.1038/nrendo.2011.153

245. Sicotte NL, Kern KC, Giesser BS, Arshanapalli A, Schultz A, Montag M, Wang H, Bookheimer SY (2008) Regional hippocampal atrophy in multiple sclerosis. Brain 131(Pt 4):1134-1141. https://doi.org/10.1093/brain/awn030

246. Dutta R, Chang A, Doud MK, Kidd GJ, Ribaudo MV, Young EA, Fox RJ, Staugaitis SM et al (2011) Demyelination causes synaptic alterations in hippocampi from multiple sclerosis patients. Ann Neurol 69(3):445-454. https://doi.org/10.1002/ana.22337

247. Rocca MA, Pravata E, Valsasina P, Radaelli M, Colombo B, Vacchi L, Gobbi C, Comi G et al (2015) Hippocampal-DMN disconnectivity in MS is related to WM lesions and depression. Hum Brain Mapp 36(12):5051-5063. https://doi.org/10.1002/ hbm.22992

248. Michelson D, Stone L, Galliven E, Magiakou MA, Chrousos GP, Sternberg EM, Gold PW (1994) Multiple sclerosis is associated with alterations in hypothalamic-pituitary-adrenal axis function. J Clin Endocrinol Metab 79(3):848-853. https://doi.org/10.1210/ jcem.79.3.8077372

249. Reder AT, Makowiec RL, Lowy MT (1994) Adrenal size is increased in multiple sclerosis. Arch Neurol 51(2):151-154

250. Wei T, Lightman SL (1997) The neuroendocrine axis in patients with multiple sclerosis. Brain 120(Pt 6):1067-1076

251. Erkut ZA, Endert E, Huitinga I, Swaab DF (2002) Cortisol is increased in postmortem cerebrospinal fluid of multiple sclerosis patients: relationship with cytokines and sepsis. Mult Scler 8(3): 229-236. https://doi.org/10.1191/1352458502ms797oa

252. Ysrraelit MC, Gaitan MI, Lopez AS, Correale J (2008) Impaired hypothalamic-pituitary-adrenal axis activity in patients with multiple sclerosis. Neurology 71(24):1948-1954. https://doi.org/10. 1212/01.wnl.0000336918.32695.6b

253. Berg D, Supprian T, Thomae J, Warmuth-Metz M, Horowski A, Zeiler B, Magnus T, Rieckmann P et al (2000) Lesion pattern in patients with multiple sclerosis and depression. Mult Scler 6(3): 156-162. https://doi.org/10.1177/135245850000600304

254. Fassbender K, Schmidt R, Mossner R, Kischka U, Kuhnen J, Schwartz A, Hennerici M (1998) Mood disorders and dysfunction of the hypothalamic-pituitary-adrenal axis in multiple sclerosis: association with cerebral inflammation. Arch Neurol 55(1):66-72

255. Gold SM, Raji A, Huitinga I, Wiedemann K, Schulz KH, Heesen C (2005) Hypothalamo-pituitary-adrenal axis activity predicts disease progression in multiple sclerosis. J Neuroimmunol 165(1-2): 186-191. https://doi.org/10.1016/j.jneuroim.2005.04.014

256. Deckx N, Lee W-P, Berneman ZN, Cools N (2013) Neuroendocrine immunoregulation in multiple sclerosis. Clin Dev Immunol 2013:23. https://doi.org/10.1155/2013/705232

257. Erkut ZA, Hofman MA, Ravid R, Swaab DF (1995) Increased activity of hypothalamic corticotropin-releasing hormone neurons in multiple sclerosis. J Neuroimmunol 62(1):27-33

258. Huitinga I, Erkut ZA, van Beurden D, Swaab DF (2004) Impaired hypothalamus-pituitary-adrenal axis activity and more severe multiple sclerosis with hypothalamic lesions. Ann Neurol 55(1):3745. https://doi.org/10.1002/ana.10766

259. Gold SM, Kruger S, Ziegler KJ, Krieger T, Schulz KH, Otte C, Heesen C (2011) Endocrine and immune substrates of depressive symptoms and fatigue in multiple sclerosis patients with comorbid major depression. J Neurol Neurosurg Psychiatry 82(7):814-818. https://doi.org/10.1136/jnnp.2010.230029 
260. Kern S, Schultheiss T, Schneider H, Schrempf W, Reichmann H, Ziemssen T (2011) Circadian cortisol, depressive symptoms and neurological impairment in early multiple sclerosis. Psychoneuroendocrinology 36(10):1505-1512. https://doi.org/ 10.1016/j.psyneuen.2011.04.004

261. Kern S, Krause I, Horntrich A, Thomas K, Aderhold J, Ziemssen $\mathrm{T}$ (2013) Cortisol awakening response is linked to disease course and progression in multiple sclerosis. PLoS One 8(4):e60647. https://doi.org/10.1371/journal.pone.0060647

262. Guzel I, Mungan S, Oztekin ZN, Ak F (2016) Is there an association between the expanded disability status scale and inflammatory markers in multiple sclerosis? J Chin Med Assoc : JCMA 79(2):54-57. https://doi.org/10.1016/j.jcma.2015.08.010

263. Dedovic K, Ngiam J (2015) The cortisol awakening response and major depression: examining the evidence. Neuropsychiatr Dis Treat 11:1181-1189. https://doi.org/10.2147/NDT.S62289

264. Vreeburg SA, Hoogendijk WJ, van Pelt J, Derijk RH, Verhagen JC, van Dyck R, Smit JH, Zitman FG et al (2009) Major depressive disorder and hypothalamic-pituitary-adrenal axis activity: results from a large cohort study. Arch Gen Psychiatry 66(6):617626. https://doi.org/10.1001/archgenpsychiatry.2009.50

265. Ulrike S, Reinhold L, Dirk H (2013) Major depression in young girls is related to altered cortisol awakening response. Eur Child Adolesc Psychiatry 22(6):379-384. https://doi.org/10.1007/ s00787-012-0371-9

266. Dienes KA, Hazel NA, Hammen CL (2013) Cortisol secretion in depressed, and at-risk adults. Psychoneuroendocrinology 38(6): 927-940. https://doi.org/10.1016/j.psyneuen.2012.09.019

267. Bhagwagar Z, Hafizi S, Cowen PJ (2005) Increased salivary cortisol after waking in depression. Psychopharmacology 182(1):54 57. https://doi.org/10.1007/s00213-005-0062-z

268. Bhagwagar Z, Hafizi S, Cowen PJ (2003) Increase in concentration of waking salivary cortisol in recovered patients with depression. Am J Psychiatry 160(10):1890-1891. https://doi.org/10. 1176/appi.ajp.160.10.1890

269. Aubry JM, Jermann F, Gex-Fabry M, Bockhorn L, Van der Linden M, Gervasoni N, Bertschy G, Rossier MF et al (2010) The cortisol awakening response in patients remitted from depression. $\mathrm{J}$ Psychiatr Res 44(16):1199-1204. https://doi.org/10.1016/j. jpsychires.2010.04.015

270. Rhebergen D, Korten NC, Penninx BW, Stek ML, van der Mast RC, Oude Voshaar R, Comijs HC (2015) Hypothalamic-pituitaryadrenal axis activity in older persons with and without a depressive disorder. Psychoneuroendocrinology 51:341-350. https://doi.org/ 10.1016/j.psyneuen.2014.10.005

271. Hsiao FH, Yang TT, Ho RT, Jow GM, Ng SM, Chan CL, Lai YM, Chen YT et al (2010) The self-perceived symptom distress and health-related conditions associated with morning to evening diurnal cortisol patterns in outpatients with major depressive disorder. Psychoneuroendocrinology 35(4):503-515. https://doi.org/ 10.1016/j.psyneuen.2009.08.019

272. Veen G, van Vliet IM, DeRijk RH, Giltay EJ, van Pelt J, Zitman FG (2011) Basal cortisol levels in relation to dimensions and DSM-IV categories of depression and anxiety. Psychiatry Res 185(1-2):121-128. https://doi.org/10.1016/j.psychres.2009.07. 013

273. Wardenaar KJ, Vreeburg SA, van Veen T, Giltay EJ, Veen G, Penninx BW, Zitman FG (2011) Dimensions of depression and anxiety and the hypothalamo-pituitary-adrenal axis. Biol Psychiatry 69(4):366-373. https://doi.org/10.1016/j.biopsych. 2010.09.005

274. van Winsen LM, Muris DF, Polman CH, Dijkstra CD, van den Berg TK, Uitdehaag BM (2005) Sensitivity to glucocorticoids is decreased in relapsing remitting multiple sclerosis. J Clin Endocrinol Metab 90(2):734-740. https://doi.org/10.1210/jc. 2004-0306
275. DeRijk RH, Eskandari F, Sternberg EM (2004) Corticosteroid resistance in a subpopulation of multiple sclerosis patients as measured by ex vivo dexamethasone inhibition of LPS induced IL-6 production. J Neuroimmunol 151(1-2):180-188. https://doi.org/ 10.1016/j.jneuroim.2004.02.009

276. Krieger S, Sorrells SF, Nickerson M, Pace TWW (2014) Mechanistic insights into corticosteroids in multiple sclerosis: war horse or chameleon? Clin Neurol Neurosurg 119:6-16. https://doi.org/10.1016/j.clineuro.2013.12.021

277. Matysiak M, Makosa B, Walczak A, Selmaj K (2008) Patients with multiple sclerosis resisted to glucocorticoid therapy: abnormal expression of heat-shock protein 90 in glucocorticoid receptor complex. Mult Scler 14(7):919-926. https://doi.org/10.1177/ 1352458508090666

278. van Winsen LM, Polman CH, Dijkstra CD, Tilders FJ, Uitdehaag BM (2010) Suppressive effect of glucocorticoids on TNF-alpha production is associated with their clinical effect in multiple sclerosis. Mult Scler 16(4):500-502. https://doi.org/10.1177/ 1352458509359721

279. Berkovich R (2013) Treatment of acute relapses in multiple sclerosis. Neurotherapeutics: J Am Soc Exp NeuroTherapeutics 10(1): 97-105. https://doi.org/10.1007/s13311-012-0160-7

280. van Winsen LML, Hooper-van Veen T, van Rossum EFC, Koper JW, Barkhof F, Polman CH, Uitdehaag BMJ Glucocorticoid receptor gene polymorphisms associated with more aggressive disease phenotype in MS. J Neuroimmunol 186(1):150-155. https:// doi.org/10.1016/j.jneuroim.2007.02.006

281. Melief J, Koper JW, Endert E, Møller HJ, Hamann J, Uitdehaag BM, Huitinga I Glucocorticoid receptor haplotypes conferring increased sensitivity $(<\mathrm{em}>\mathrm{Bcl}</ \mathrm{em}>\mathrm{I}$ and N363S) are associated with faster progression of multiple sclerosis. J Neuroimmunol 299:84-89. https://doi.org/10.1016/j.jneuroim.2016.08.019

282. Kassi E, Semaniakou A, Sertedaki A, Evangelopoulos ME, Kazazoglou T, Kominakis A, Sfagos C, Charmandari E et al (2016) Sequencing analysis of the human glucocorticoid receptor (NR3C1) gene in multiple sclerosis patients. J Neurol Sci 363: 165-169. https://doi.org/10.1016/j.jns.2016.02.054

283. Webster JC, Oakley RH, Jewell CM, Cidlowski JA (2001) Proinflammatory cytokines regulate human glucocorticoid receptor gene expression and lead to the accumulation of the dominant negative $\beta$ isoform: a mechanism for the generation of glucocorticoid resistance. Proc Natl Acad Sci 98(12):6865-6870. https:// doi.org/10.1073/pnas.121455098

284. Tsitoura DC, Rothman PB (2004) Enhancement of MEK/ERK signaling promotes glucocorticoid resistance in CD4+ T cells. J Clin Invest 113(4):619-627. https://doi.org/10.1172/jci18975

285. Raison CL, Capuron L, Miller AH (2006) Cytokines sing the blues: inflammation and the pathogenesis of depression. Trends Immunol 27(1):24-31. https://doi.org/10.1016/j.it.2005.11.006

286. Gold SM, Sasidhar MV, Lagishetty V, Spence RD, Umeda E, Ziehn MO, Krieger T, Schulz KH et al (2012) Dynamic development of glucocorticoid resistance during autoimmune neuroinflammation. J Clin Endocrinol Metab 97(8):E1402-E1410. https://doi.org/10.1210/jc.2012-1294

287. Pariante CM, Miller AH (2001) Glucocorticoid receptors in major depression: relevance to pathophysiology and treatment. Biol Psychiatry 49(5):391-404

288. Carvalho LA, Bergink V, Sumaski L, Wijkhuijs J, Hoogendijk WJ, Birkenhager TK, Drexhage HA (2014) Inflammatory activation is associated with a reduced glucocorticoid receptor alpha/ beta expression ratio in monocytes of inpatients with melancholic major depressive disorder. Transl Psychiatry 4:e344. https://doi. org/10.1038/tp.2013.118

289. Thiagarajah AS, Eades LE, Thomas PR, Guymer EK, Morand EF, Clarke DM, Leech M (2014) GILZ: glitzing up our understanding 
of the glucocorticoid receptor in psychopathology. Brain Res 1574:60-69. https://doi.org/10.1016/j.brainres.2014.06.008

290. Torrego A, Pujols L, Roca-Ferrer J, Mullol J, Xaubet A, Picado C (2004) Glucocorticoid receptor isoforms alpha and beta in in vitro cytokine-induced glucocorticoid insensitivity. Am J Respir Crit Care Med 170(4):420-425. https://doi.org/10.1164/rccm.200308$1143 \mathrm{OC}$

291. Carvalho LA, Juruena MF, Papadopoulos AS, Poon L, Kerwin R, Cleare AJ, Pariante CM (2008) Clomipramine in vitro reduces glucocorticoid receptor function in healthy subjects but not in patients with major depression. Neuropsychopharmacol : Off Publ Am Coll Neuropsychopharmacol 33(13):3182-3189. https://doi.org/10.1038/npp.2008.44

292. Carvalho LA, Torre JP, Papadopoulos AS, Poon L, Juruena MF, Markopoulou K, Cleare AJ, Pariante CM (2013) Lack of clinical therapeutic benefit of antidepressants is associated overall activation of the inflammatory system. J Affect Disord 148(1):136-140. https://doi.org/10.1016/j.jad.2012.10.036

293. Nikkheslat N, Zunszain PA, Horowitz MA, Barbosa IG, Parker JA, Myint AM, Schwarz MJ, Tylee AT et al (2015) Insufficient glucocorticoid signaling and elevated inflammation in coronary heart disease patients with comorbid depression. Brain Behav Immun 48:8-18. https://doi.org/10.1016/j.bbi.2015.02.002

294. Cohen S, Janicki-Deverts D, Doyle WJ, Miller GE, Frank E, Rabin BS, Turner RB (2012) Chronic stress, glucocorticoid receptor resistance, inflammation, and disease risk. Proc Natl Acad Sci U S A 109(16):5995-5999. https://doi.org/10.1073/pnas. 1118355109

295. Miller GE, Chen E, Sze J, Marin T, Arevalo JM, Doll R, Ma R, Cole SW (2008) A functional genomic fingerprint of chronic stress in humans: blunted glucocorticoid and increased NFkappaB signaling. Biol Psychiatry 64(4):266-272. https://doi. org/10.1016/j.biopsych.2008.03.017

296. Slavich GM, Irwin MR (2014) From stress to inflammation and major depressive disorder: a social signal transduction theory of depression. Psychol Bull 140(3):774-815. https://doi.org/10. 1037/a0035302

297. Bauer ME, Papadopoulos A, Poon L, Perks P, Lightman SL, Checkley S, Shanks N (2003) Altered glucocorticoid immunoregulation in treatment resistant depression. Psychoneuroendocrinology 28(1):49-65

298. Kipnis J, Derecki NC, Yang C, Scrable H (2008) Immunity and cognition: what do age-related dementia, HIV-dementia and 'chemo-brain' have in common? Trends Immunol 29(10):455-463. https://doi.org/10.1016/j.it.2008.07.007

299. Wolf SA, Steiner B, Akpinarli A, Kammertoens T, Nassenstein C, Braun A, Blankenstein T, Kempermann G (2009) CD4-positive T lymphocytes provide a neuroimmunological link in the control of adult hippocampal neurogenesis. J Immunol (Baltimore, Md : 1950) 182(7):3979-3984. https://doi.org/10.4049/jimmunol. 0801218

300. Lapolla A (1965) Clinical trial of a new antidepressant (desipramine hydrochloride) in a hospital setting. Am J Psychiatr 121(12): 1206-1208. https://doi.org/10.1176/ajp.121.12.1206

301. Mendels J, Schless AP (1977) Antidepressant effects of desipramine administered in two dosage schedules. Dis Nerv Syst 38(4): 249-251

302. Olivier-Martin R, Marzin D, Buschsenschutz E, Pichot P, Boissier J (1975) Concentrations plasmatiques de l'imipramine et de la desmethylimipramine et effet anti-depresseur au cours d'un traitement control. Psychopharmacologia 41(2):187-195. https:// doi.org/10.1007/bf00421078
303. Glassman AH (1977) Clinical implications of imipramine plasma levels for depressive illness. Arch Gen Psychiatry 34(2):197. https://doi.org/10.1001/archpsyc.1977.01770140087010

304. Reisby N, Gram LF, Bech P, Nagy A, Petersen GO, Ortmann JR, Ibsen I, Dencker SJ et al (1977) Imipramine: clinical effects and pharmacokinetic variability. Psychopharmacology 54(3):263272. https://doi.org/10.1007/bf00426574

305. Mindham RH (1982) Tricyclic antidepressants. In: Tyrer PJ (ed) Drugs in psychiatric practice. Butterworths, London

306. Guemei AA, El Din NMN, Baraka AM, El Said DI (2008) Do desipramine [10,11-Dihydro-5-[3-(methylamino) propyl]-5Hdibenz[b,f]azepine monohydrochloride] and Fluoxetine [NMethyl-3-phenyl-3-[4-(trifluoromethyl)phenoxy]-propan-1amine] ameliorate the extent of colonic damage induced by acetic acid in rats? J Pharmacol Exp Ther 327(3):846-850. https://doi. org/10.1124/jpet.108.141259

307. Song C, Killeen AA, Leonard BE (1994) Catalase, superoxide dismutase and glutathione peroxidase activity in neutrophils of sham-operated and olfactory-bulbectomised rats following chronic treatment with desipramine and lithium chloride. Neuropsychobiology 30(1):24-28

308. Kumar A, Garg R (2009) Protective effects of antidepressants against chronic fatigue syndrome - induced behavioral changes and biochemical alterations. Fundam Clin Pharmacol 23(1):89 95. https://doi.org/10.1111/j.1472-8206.2008.00638.x

309. Gaur V, Kumar A (2010) Protective effect of desipramine, venlafaxine and trazodone against experimental animal model of transient global ischemia: possible involvement of NO-cGMP pathway. Brain Res 1353:204-212. https://doi.org/10.1016/j. brainres.2010.07.004

310. Vircheva S, Nenkova G, Georgieva A, Alexandrova A, Tzvetanova E, Mateeva P, Zamfirova R, Kirkova M (2011) Effects of desipramine on the antioxidant status in rat tissues at carrageenan-induced paw inflammation. Cell Biochem Funct 30(1):18-23. https://doi.org/10.1002/cbf.1812

311. Bravo JA, Díaz-Veliz G, Mora S, Ulloa JL, Berthoud VM, Morales P, Arancibia S, Fiedler JL (2009) Desipramine prevents stress-induced changes in depressive-like behavior and hippocampal markers of neuroprotection. Behav Pharmacol 20(3):273-285. https://doi.org/10.1097/fbp.0b013e32832c70d9

312. Smith MA, Makino S, KvetŇAnskÝ R, Post RM (1995) Effects of stress on neurotrophic factor expression in the rat brain. Ann N Y Acad Sci 771(1 stress):234-239. https://doi.org/10.1111/j.17496632.1995.tb44684.x

313. Loder C, Allawi J, Horrobin DF (2002) Treatment of multiple sclerosis with lofepramine, 1-phenylalanine and vitamin B12: mechanism of action and clinical importance: roles of the locus coeruleus and central noradrenergic systems. Med Hypotheses 59(5):594-602. https://doi.org/10.1016/s0306-9877(02)00261-x

314. Wade DT (2002) A randomised placebo controlled exploratory study of vitamin B-12, lofepramine, and L-phenylalanine (the "Cari Loder regime") in the treatment of multiple sclerosis. J Neurol Neurosurg Psychiatry 73(3):246-249. https://doi.org/10. 1136/jnnp.73.3.246

315. Saeed N, Puri BK, Oatridge A, Hajnal JV, Young IR (1998) Two methods for semi-automated quantification of changes in ventricular volume and their use in schizophrenia. Magn Reson Imaging 16(10):1237-1247. https://doi.org/10.1016/s0730-725x(98) 00128-3

316. Puri BK, Bydder GM, Chaudhuri KR, Al Saffar BYS, Curati WL, White SJ, Mitchell L, Hajnal JV et al (2001) MRI changes in multiple sclerosis following treatment with lofepramine and 1-phenylalanine. Neuroreport 12(9):1821-1824. https://doi.org/10. 1097/00001756-200107030-00012 